Micro-foundational ambidexterity and multinational enterprises: a systematic review and a conceptual framework

\title{
Authors details
}

Michael Christofi*

University of Nicosia

46 Makedonitissas Avenue, CY-2417

P.O.Box 24005, CY-1700, Nicosia, Cyprus

Tel.: +35722842054

E-mail: christofi.mi@unic.ac.cy

*Corresponding author

Demetris Vrontis

University of Nicosia

46 Makedonitissas Avenue, CY-2417

P.O.Box 24005, CY-1700, Nicosia, Cyprus

Tel.: +357 22842026, f: + 35722842050

E-mail: vrontis.d@unic.ac.cy

John W. Cadogan

Loughborough University

Epinal Way, Loughborough

Leicestershire,

LE11 3TU, UK

Tel.: + 44 (0)1509 228846

E-mail: J.W.Cadogan@,lboro.ac.uk 


\title{
Micro-foundational ambidexterity and multinational enterprises: a systematic review and a conceptual framework
}

\begin{abstract}
During the past decade, ambidexterity research has broadened from its traditional macro-level focus to examine the micro-level perspectives of ambidexterity on various settings. The authors systematically review and critically appraise the literature of ambidexterity from a microfoundational perspective, within the context of Multinational Enterprises (MNEs). By synthesizing the review findings, the authors develop a comprehensive framework that maps extant literature within and across various disciplines and multiple levels of analysis. As part of their review, the authors also identify and discuss important emerging themes and fruitful areas for future research and present the implications to both research and management practice.
\end{abstract}

Keywords: micro-foundations of ambidexterity; conceptual framework; systematic review; Multinational enterprises. 


\section{Introduction}

Ambidexterity, which refers to the ability of businesses to engage in exploitation activities of their existing capabilities, whereas at the same time to explore new ones, has emerged as a significant research domain in the management research (Dezi et al. 2019; Ferraris et al. 2019; Chebbi et al. 2015; Junni et al. 2015; Junni et al. 2013). In particular, exploration enables organizations to adapt and apply new knowledge. Exploitation, allows organizations to enhance their operational efficiency (Luger et al. 2018). Based on this, the eternal challenge that forms the theoretical basis of the ambidexterity concept is that exploitation and exploration activities are opposite forces, and companies need to reconcile their paradoxical organizational demands to achieve superior and sustainable long-term performance (Ferraris et al. 2018; Luger et al. 2018; Raisch and Birkinshaw, 2008).

A closer look of extant literature on ambidexterity reveals two main research trends. First, ambidexterity literature has focused on two research streams, the micro-level and the traditional macro-level perspectives of ambidexterity (Felin et al. 2015). Second, ambidexterity research has spread and applied across various disciplines, including the international business field with the main focus being the context of multinational enterprises (Haas, 2010; Hughes et al. 2010), as it provides various benefits, such as superior internationalization (Han, 2007) firm performance (Vrontis et al. 2017), and successful global acquisitions of emerging market multinationals (Nicholson et al. 2016), among others.

This interest in ambidexterity within an MNE context is also shown in practice, whereas large MNEs, such as $\mathrm{AB}$ Volvo and IKEA embraced the concept of ambidexterity in their core organizational tenets in order to successfully thrive in the global arena (Vahlne and Jonsson, 2017). However, despite the increasing interest of MNEs in developing ambidexterity, there was no attempt from scholarly research to map and structure extant research in a systematic way, especially on the micro-foundational aspect of ambidexterity. Adding to this, the complex 
nature of the concepts involved, such as the challenges, issues and propositions related with MNEs compared to domestic businesses (Rozen-Bakher, 2018; Sefiani et al. 2018; Schuler et al. 1993) requires a thorough overview of extant research in order to better understand the current state of knowledge. Moreover, this research stream tends to be fragmented as it is based on a variety and differing disciplinary and conceptual lenses, which has resulted in the absence of an integrative framework.

Based on these realities the aim of this study is to fill this gap, thereby increasing our understanding of the relationship between micro-level ambidexterity and MNEs. Thus, the main objectives of this study are: (1) to systematically review and critically analyze the current level of micro-level ambidexterity research on MNEs; (2) to synthesize the review findings into a comprehensive multi-dimensional and multi-disciplinary framework, and; (3) to identify knowledge gaps and provide fruitful directions for future research.

Our study contributes in various ways to scholarly research and management practice. First, we advance our understanding on the micro-foundational perspective of ambidexterity research in the context of MNEs. Second, we offer the first systematic review of extant research on the micro-foundations of ambidexterity and MNEs, which maps extant literature. Third, we develop a comprehensive multi-dimensional and multi-disciplinary framework that organizes extant literature. Fourth, we identify various knowledge gaps, emerging themes and limitations of extant research, through which we offer a promising future research agenda. Finally, our study provides a guiding tool for executives in MNEs in developing ambidexterity within their organization in order to benefit from its various outcomes.

The rest of this paper is organized as follows. In the following section, we define the microfoundational perspective of ambidexterity based on the focus of this review. Next, we provide a rational for undertaking a systematic review methodology and in the following section we describe the systematic review methodology and data collection process. In the next section we 
provide a descriptive and thematic analysis of the findings. Following, in the synthesis section we categorize and analyse the findings and present a comprehensive conceptual framework. Lastly, we present the contributions of this review, identify the limitations of our study and provide avenues for further research.

\section{Towards a micro-foundational perspective of ambidexterity in MNE research}

Micro-foundations are a movement and way of conceptualizing, rather than a theory per se, that has suffused across a wide array of macro-level theories and concepts (Felin et al. 2015). The interest of the scholar community on the concept of micro-foundations in the fields of strategy and organization theory has increased dramatically over the past decade (e.g. Teece, 2007; Felin \& Foss, 2005; Lippman \& Rumelt, 2003). The main objective of the microfoundations research stream has been to comprehend how individual-level variables affect businesses, how the interaction of individuals leads to emergent, collective, and organizationlevel performance and outcomes, and how these micro-level variables mediate or moderate the relationships between macro-level factors (i.e., Abell et al. 2008). For instance, stating that a network relationship is the source of value for a company would lead researchers focusing on micro-foundations to investigate the origins of that network or relationships, the causal antecedents (Felin et al. 2015).

Initial calls for micro-foundations research (e.g. Gavetti, 2005; Felin \& Foss, 2005; Lippman \& Rumelt, 2003) have led to subsequent research on micro-foundations by scholars from other business fields. According to Felin et al. (2015), there has now been research, among others, on the micro-foundations of absorptive capacity (Volberda, Foss, \& Lyles, 2010), organizational capabilities (Kemper et al. 2013), routines (e.g. Miller et al. 2014; Loch et al. 2013; Winter, 2013 Bapuji et al. 2012), performance (Foss \& Lindenberg, 2013; Lindenberg \& Foss, 2011; Eisenhardt et al. 2010), institutional logics (Thornton et al. 2012), firm R\&D (Paruchuri \& Eisenman, 2012), stakeholder management (Bridoux \& Stoelhorst, 2014), 
innovation (Grigoriou \& Rothaermel, 2014), networks (Ahuja et al. 2012), the RBV (Foss, 2011) and ambidexterity (Rogan \& Mors, 2014). Evidence of the micro-foundations movement can also be seen in recent journal special issues focused to the concept of micro-foundations, as well as its relationship with other domains (e.g. Devinney, 2013; Felin et al. 2012).

Moreover, in extant literature, a core argument among the various conceptualizations of the notion of micro-foundations is what researchers refer to, the micro-foundations as levels argument. Based on this, developing micro-foundations are about finding the explanation of a consequence, or the causes of a phenomenon at a lower level of analysis than the phenomenon under investigation (Felin et al. 2015). For instance, various researchers refer to microfoundations of ambidexterity at the team level of analysis as well (e.g., Haas, 2010). Based on this, our review focused on individual and team level ambidexterity on the one hand, and MNE research on the other hand.

\section{Why a systematic review}

The aim of this review is to provide a rigorous assessment of the literature on MNEs and their link with individual and team level ambidexterity. The systematic review methodology refers to a review of extant research on a clearly formulated question that applies systematic and explicit methods to identify, choose and critically analyse relevant research, and to extract and analyse findings and data from the chosen studies for review (Christofi et al. 2017; De Menezes $\&$ Kelliher, 2011). This review method originates from the medical sciences, but, over the years has spread and used by researchers in the business field as well (De Menezes \& Kelliher, 2011; Tranfield et al. 2003). A systematic review provides a thorough methodology for assessing extant knowledge using a multi-level review strategy (Turner et al. 2013; Pittaway et al. 2004). A systematic review differs from a traditional narrative review as it applies a replicable, scientific and transparent procedure which aims to reduce bias via thorough literature searches (Vrontis \& Christofi, 2019; De Menezes \& Kelliher, 2011). Thus, such reviews are increasingly 
favoured over traditional narrative methods in recent years, based on the premise that they increase the rigour, validity and generalizability of findings (Stumbitz et al. 2018; Jones and Gatrell 2014), whereas the latter draw on a non-replicable methodology in which the sources identified have not been selected and analyzed based on systematic criteria (Boiral et al. 2018). Moreover, a systematic review is not a meta-analysis, which focuses on empirical studies that apply a quantitative methodology, and specifically on the aggregate correlation structure of their data (Tranfield et al. 2003). Adding to this, meta-analyses presuppose a high degree of agreement across different studies in relation to the measurement of dependent and independent variables, research strategy, study sample and context and the statistical methodology to data analysis (Sousa et al. 2008). Furthermore, a systematic review differs from a content analysis through which exploratory and predictive articles are categorized based on their main content and themes (De Menezes \& Kelliher, 2011).

Based on this, we decided to apply a systematic review methodology instead of a narrative review in order to provide a replicable, rigorous, and transparent assessment of extant literature on the link between individual and team (micro) level ambidexterity with MNC research. Moreover, this review was interested in empirical studies that apply either quantitative, qualitative or both methodologies, as well as conceptual or theoretical studies. Therefore, we could not apply a meta-analysis that includes only empirical studies that apply a specific form of methodology. Also, we favoured the systematic review methodology over the content analysis, as we aimed on providing both a descriptive and thematic analysis of extant research and synthesizing the findings by means of a holistic integrative framework. Finally, given the fragmented and inter-disciplinary nature of our field of study, we apply a systematic review methodology as a guiding tool (Stumbitz et al. 2018; Wang and Chugh 2014), and apply an approach characterized by compliance and flexibility (Stumbitz et al. 2018; Mallett et al. 2012). 
We followed Tranfield et al. (2003) three-stage process: data collection, descriptive and thematic analysis of data, and data synthesis. During the first stage, we defined the review question, boundaries and protocols of the research. Then, we identified, accessed, and judged the quality and relevance of the identified literature in accordance with the topic under review. The next step involved a descriptive and thematic analysis of the findings in order to map the literature, identify possible gaps and inconsistencies, and ground propositional conclusions as to where MNC and micro-level ambidexterity research could be directed in future. At the third and final stage, we synthesized the findings into an integrative, multi-disciplinary and multidimensional conceptual framework of micro-level ambidexterity in the context of MNCs.

\section{Methodology Process and data collection}

A systematic review is driven by a review question, from which search strings for the scientific database searches are defined (Xiao \& Nicholson, 2013). In this paper, the review question was: 'What we know and don't know about Multinational Enterprises and ambidexterity from a micro-foundational point of view?'. In terms of the micro-level concept of ambidexterity analysed in the previous section, we included studies focusing on the individual or team level antecedents of ambidexterity and how these variables affect MNEs, how individual or team level ambidexterity is formed within the context of MNEs, and how these micro-level variables or outcomes of ambidexterity impact, mediate or moderate the relationships between macrolevel factors within the context of MNEs. Moreover, we included studies that focused on macro-level antecedent of ambidexterity that explain micro-level outcomes, such as individual or team ambidexterity in MNEs. As regards to the boundary of a multinational enterprise, we apply the definition stated in Geppert and Dörrenbächer (2014) which refers to MNCs as networks composed by a Headquarter (HQ) and rationally behaving subunits, their subsidiaries. Thus, we included studies focusing on MNEs and their HQs, as well as research 
focusing MNC's subsidiaries. Moreover, we included studies that drew on samples from MNCs and/ or their subsidiaries.

Following other state-of-the-art systematic reviews (i.e., Nadeem et al. 2018; Alzahrani et al. 2017; Leonidou et al. 2018; Christofi et al. 2017; Rajwani \& Liedong, 2015; Baron et al. 2014; Xiao \& Nicholson, 2013; Christoffersen, 2013), we searched within EBSCO, ScienceDirect, and Emerald Fulltext on-line databases. Given our intention to capture all relevant research, we did not include a specific timeframe for our search. Continuing, as usually done in systematic literature reviews, we searched the titles, abstracts and keywords of journal articles (Pisani et al. 2017; Aguinis \& Glavas, 2012), using combinations of keywords drawn from lists indicative of the term multinational enterprise and of the concept of ambidexterity. We modelled the scope and structure of our search string strategy on other literature reviews. Thus, as a search strategy for the term ambidexterity we followed Turner et al. (2013), and for capturing all relevant articles relating to the term multinational enterprises, we followed systematic reviews that focused on international business research (Pisani et al. 2017) or multinational enterprises ( $\mathrm{Li}$ et al. 2016; Horwitz, 2015). Based on this, we developed and applied the following keyword search algorithm: ("ambidexterity" or "ambidextrous") AND (“multinational” OR “international” OR "transnational” OR "global” OR "geographic space” OR “FDI” OR ”Foreign Direct Investment” OR “distance” OR “subsidiary” OR “regional” OR "MNE” OR “MNEs" OR "MNC" OR “MNCs"). As this search string formula did not yield any results at Emerald on-line database (only 2 articles were identified), we decided to use a more general approach for this database so as to capture all relevant literature from this Emerald as well. Thus, we searched on titles, abstracts and keywords of journal articles using the search strings 'ambidexterity' OR 'ambidextrous'.

The keywords used, resulted in an initial sample of 502 references. The initial pool was refined further in order to identify peer-reviewed journal articles that match the research question. 
Three specific exclusion criteria were used to distil the final data set. First, as the source of data, we only included articles published in peer-reviewed journals, because they are widely regarded as including validated knowledge that is likely to influence the field (López-Duarte et al. 2016; Xiao \& Nicholson, 2013; Podsakoff et al. 2005). Therefore, following other systematic reviews (e.g., Christofi et al. 2017; López-Duarte et al. 2016) we excluded articles published in non- academic peer review journals, editorials, book chapters, commentaries, secondary articles, short communication articles, executive summaries, viewpoints, or conference proceedings. However, our review was not limited to specific journals or research areas, but included all articles focused on or that cited work that focuses in this area. Second, we excluded articles published in a non-English language (Rashman et al. 2009), due to language limitations of the researchers. Third, as the overall aim of the analysis was the identification of micro-level ambidexterity research on MNEs, we excluded studies focusing on international business research but not on MNCs, or on MNCs but not on ambidexterity at the individual or team level of analysis.

Having establish a common operational definition as regards to ambidexterity and MNCs for subsequent analysis on the identified articles, we followed López-Duarte et al (2016) and we applied a qualitative approach based on two authors' reading of these abstracts in order to take a decision on whether or not the identified studies matched with our intended review focus. Thus, after excluding non-English papers, or non-peer review academic articles, we manually read the titles, abstracts and keywords of 379 studies in terms of relevance. Adding to this, if a paper was classified as focusing on individual and team level ambidexterity, but not having any indication as regards to its focus on MNEs in the title, abstract or keywords, we reviewed the sample in order to clarify if it was drawn on international companies/ MNEs. From the 379 articles we removed 110 duplicates and we excluded 185 studies that were non-relevant to ambidexterity or ambidexterity in MNEs. In 84 cases we read the entire article because we 
were unsure whether its focus was relevant or if it captured the micro-foundational perspective of this review. After this screening process, 19 studies were selected as being relevant to the review question.

Next, following Rajwani and Liedong (2015) and Nofal et al. (2018), we employed a backward and forward snowballing process by manually searching the references of all selected articles. This additional step provided another five journal papers (van der Borgh and Schepers, 2014; Mom et al. 2009; Nemanich and Vera, 2009; Atuahene-Gima \& Murray, 2007; Mom et al. 2007). These journal articles were also assessed based on the inclusion and exclusion criteria using a title, abstract and sample analysis. Lastly, to further ensure that we did not exclude related studies, we included an additional literature search step, which was based on experts' opinions (Nofal et al. 2018). We showed our list of identified articles to two experts in the area and asked them if there are other journal articles relevant to the topic that our review process had failed to identify. This additional step yielded two more articles (Junni et al. 2015; Kostopoulos et al. 2015). Our overall search yielded a final number of 26 published journal articles. To enhance the transparency of our review method, an overview of the applied research process is presented in Figure 1.

\section{"Insert Figure 1 about here"}

Relevant data from all 26 articles were then extracted to a data extraction form (Tranfield et al. 2003) designed to capture the publication details, authors' characteristics, type of paper, methods, industry context, unit of analysis and key findings in the literature. The development of a data extraction form aided reading and deployment of the descriptive and thematic analysis of the reviewed field (mapping the field of research), as well as the understanding of relationships and interrelationships between the concepts and findings in order to synthesize the findings into a comprehensive framework. 


\section{Data Analysis}

We start our analysis by considering journal outlets. We continue with the types of papers identified, the methods used and their industry focus. Then we analyse the geographic distribution of authors and data. We conclude with an analysis of the unit of analysis that the selected studies focused on, as well as the theories they applied. This type of analysis provides us with information regarding emerging patterns of geographical coverage, theories drawn upon, and research methodologies applied. For instance, the number of qualitative studies provides insights as regards to the extent to which authors provided an in-depth analysis of various aspects within this research stream.

\section{Journal Outlets}

The 4 journals with the highest number of micro-level ambidexterity - MNC research articles (2 publications each) are Journal of World Business, Journal of Business Strategy, Journal of Organizational Effectiveness: People and Performance, and Human Resource Management (USA). Micro-level ambidexterity - MNC research is predominantly published in General Management journals $(19 \%, n=5)$, as well as Human Resource Management journals (19\%, $\mathrm{n}=5)$, followed by International Business $(15 \%, \mathrm{n}=4)$, Innovation $(12 \%)$, marketing $(8 \%, \mathrm{n}=2)$, Organization Science $(8 \%, n=2)$, Strategy $(8 \%, n=2)$, Information Management $(4 \%, n=1)$, Management Development and Education (4\%, $n=1)$, and Social Science $(4 \%, n=1)$ journals (Figure 2).

\section{"Insert Figure 2 about here"}

This probably relates to the fact that the largest portion of micro-level ambidexterity - MNC studies is conducted by Management or HRM scholars that examine characteristics of individuals and teams in an MNC context, while research from IB scholars on how MNCs can be ambidextrous is still in its infancy. Table 1 also offers the opportunity to compare field journal clusters separately. 
"Insert Table 1 about here"

Even though the number of published articles has recently increased in both international business and strategy journals, the scholarly research on micro-level ambidexterity - MNC research is largely confined to HRM. The narrow nature of the field indicates that micro-level ambidexterity - MNC research is a niche that is not communicated very well to scholars outside Management/ HRM departments. This shows a problematic situation because, micro-level ambidexterity - MNC is interdisciplinary in nature and researchers from various disciplines should have open communication channels in order to share and further build upon extant literature.

Although the largest share of micro-level ambidexterity - MNC research is published in General Management and HRM journals, the most impactful micro-level ambidexterity - MNC studies appear in a variety of publication outlets. To have a better understanding about the impact of the publication outlets on the micro-level ambidexterity - MNC field, we explore our sample's number of citations. The 5 most cited papers are Mom et al. (2009; 479 citations; organization studies field); Mom et al. (2007; 464 citations; General Management); AtuaheneGima et al. (2007; 411 citations; Marketing); Nemanich and Vera (2009; 255 citations; organization studies); and Haas (2010; 166 citations; General Management).

Also, we find that the most cited micro-level ambidexterity - MNC articles, based on first author's geographical location (Figure 3) are dominated by European scholars ( $n=17,65 \%)$ followed by Asian ( $n=5,19 \%)$, American $(n=3,12 \%)$ and Australian $(n=1,4 \%)$ researchers. Again, this is problematic because by nature, micro-level ambidexterity - MNC is international, thus, scholars from other parts of the world, such as Australia and Africa should also investigate and contribute to this emerging and very interesting research stream. Especially for the African continent, this finding agrees with the general trend that research within this continent remains limited (George et al. 2016). Hence, strategy and international business 
scholars should focus on this continent as well, as it provides fruitful directions for further research.

\section{"Insert Figure 3 about here"}

The most cited articles are published in Organization Science, Journal of Management Studies, Journal of International Marketing, the Leadership Quarterly and Academy of Management Journal and thus not strictly confined to General Management or HRM journals. The crossdisciplinary nature of extant research is encouraging, as it provides an indication of prominence and promise of the micro-level ambidexterity - MNC research domain. Furthermore, these articles are published within the premier journals of their respective field and represent core, often influential contributions across a variety of fields, including leadership characteristics, international marketing research, new venture internationalization, and new product development. While the "infancy" feature of micro-level ambidexterity - MNC research is highlighted in previous research (e.g., Haas, 2010), we find that the research productivity on the topic has greatly accelerated over the past five years with nearly half of the studies $(45 \%)$ have been published since 2013, indicating that the research domain of micro-level ambidexterity - MNC is rapidly transitioning into an "emerging" stage.

\section{Paper type, methodology and industry analysis}

The results of our literature search show that from the entire set of 26 articles, almost all articles are empirical in nature $(96 \% ; n=25)$, whereas no conceptual studies were found articles. We also identified 1 literature review that focused on multiple levels of analysis. This finding indicates that the relevant literature is characterized by imbalance between conceptual and empirical articles, with the former being literally absent. This is a very problematic finding as conceptual contributions tend to provide the basis for future empirical research and expand the theoretical boundaries of the research area. Thus, scholars should 
focus on developing the theoretical basis of micro-level ambidexterity - MNC research for further evolving the domain and expanding its boundaries into new grounds.

In terms of methodologies applied by the selected studies, there is an even distribution between qualitative and quantitative studies, capturing 48\% (12 studies) from the total sample respectively. However, taking the time of publication into consideration (Figure 4) we can see that there is an increasing trend of the use of qualitative methods, as before 2013 there was only 1 qualitative (out of seven) studies, whereas after 2013 the majority of studies (11 out of 18 studies) follow a qualitative approach. The application of both qualitative and quantitative methods (mixed methods approach) was rarely used among our consideration set (1 study).

\section{"Insert Figure 4 about here"}

Service sector studies capture the largest part of our sample (with these focusing mostly on high technology, electronics, telecommunication, and information technology). The manufacturing sector represented a fifth (20\%) of the empirical articles in total, however, the retail sector was the least studied $(4 \% ; n=1)$. The service sector captures almost one sixth of the empirical studies $(16 \% ; n=4)$, focusing mostly on the financial and professional services. Four studies had no indication of their industrial focus, whereas 16\% (4 studies) reported on mixed sector studies (Table 2).

"Insert Table 2 about here"

\section{Geographic Analysis of Authorship and Data}

As expected, single authorship articles were least published - representing just $4 \%(n=1)$. Approximately half of the articles $(42 \% ; n=11)$ were written by two authors and the majority of articles $(54 \% ; n=14)$ were written by three or more authors (Table 3). Overall, we identify 75 authors from 59 universities and institutions in 41 countries, whereas the United Kingdom and Netherlands prevail, followed by China and USA. In spite of the geographical diversity, 
$62 \%$ are written by one or multiple authors that are affiliated with one country, compared to $23 \%$ in two and $15 \%$ in three or more countries. This finding that only a small share of microlevel ambidexterity - MNC research is represented by an international author team is striking, given the plethora of available technologies that enable cross-country collaboration. Our findings denote that there is an important potential for international research collaboration. In terms of country coverage by primary data, the number of countries studied in micro-level ambidexterity - MNC articles ranges from 1 to 7 whereas the focus on developed countries dominates. We did not identify any pattern between the number of countries studied and time, a finding which suggests that authors do not use the abundance of international comparative data sets that are publicly available in todays' era and cover several countries. Historically, articles with an author team from two or three countries use empirical data gathered from their affiliated geographical territories (Terjesen et al. 2016). In recent years, researchers use data that come from geographical territories outside their countries; it is common to find two or three researchers from the same country, publishing findings from regression analyses from 40 countries (Terjesen et al. 2016). Altogether, the geographic analysis illustrates great asymmetry as our sample incorporates data from 39 countries, but authors hail from 45 countries. Also, this research stream aligns with the recent increase of the research focus on emerging and transitioning markets, with $23 \%$ ( $n=6$; excluding studies that provide no information) of studies including the BRIC (Brazil, Russia, India, and China) context.

\section{"Insert Table 3 about here"}

\section{Level of Analysis and Theoretical Base of Studies}

Regarding the level-of-analysis, there is an almost even distribution of studies focusing on the individual $(n=9,35 \%)$ and team/ project level of analysis $(n=7,27 \%)$. The vast majority of articles focuses on multiple levels (10 studies, 38\%) including, individual, team, intraorganizational, and inter-organizational levels of analysis. When the year of publication is 
taken into consideration, it becomes clear that this research area and the evidence base shifts from the single-level of analysis to a multiple level of analysis. For example, from 2007 - 2013, only 1 article focused on multiple levels of analysis, whereas from 2014 onwards the number of articles raised to 10 .

The findings of the review indicate that management, international business, innovation, strategy, and marketing scholars draw on theories from several disciplines. The findings indicate that intellectual capital theory was most applied by the existing literature (Fu et al. 2016; Kostopoulos et al. 2015; Turner \& Lee-Kelley, 2013; Turner et al. 2013). Other theories include, knowledge inflows (Mom et al. 2007), social capital (Atuahene-Gima \& Murray, 2007), leadership and social learning theory (Nemanich \& Vera, 2009), task autonomy and control theory (Van der Borgh \& Schepers, 2014), paradox theory and the attention-based view of the firm (Birkinshaw et al. 2016), cognitive evaluation and emotional intelligence (Kao et al. 2016), organiational learning (Yan et al. 2016), business model innovation (Gebauer et al. 2017), dynamic capabilities, (Vahlne \& Jonsson, 2017) knowledge management and information and communication technologies capabilities (Bresciani et al. 2018), and organizational routines (Snehvrat \& Dutta, 2018). However, $40 \%$ of the studies $(n=10$, excluding the literature review article) were defined as 'unspecified' as in several cases no theory was applied by the authors. In particular, for some of these cases, the theories drawn upon were not made clear in the text, whereas in some other cases the authors referred in general to the existing ambidexterity literature. Hence, as it is shown by the findings, empirical studies lack from a strong theoretical base of well-grounded and established theories from the various business fields. Consequently, scholars should apply a wider variety of theoretical notions to develop better-constructed empirical and theoretical studies, as well as to enhance multidisciplinary cross-fertilization of ideas, theories, and constructs from international business, strategy, organization science, human resource management or psychology. 
A summary of the 26 empirical studies included in this review is presented in Table 4, whereas the next section discusses the findings of the systematic review in more detail.

"Insert Table 4 about here"

\section{Synthesis}

This section analyses and synthesizes the data identified in this review into a comprehensive, multidisciplinary, and multidimensional framework of micro-level ambidexterity in MNEs (see figures 6 and 7). By applying the pattern-matching technique (Crossan and Apaydin, 2010; Yin, 1994), we organize the dimensions of micro-level ambidexterity which emerged from the literature findings into two broad categories. The first category, namely individual, incorporates those antecedents of ambidexterity, that focus on individual characteristics of employees within an organization, as well as their outcomes at all levels of analysis. The second category, namely structures and procedures, includes those antecedents of ambidexterity which relate to the structural and procedural characteristics within an MNE for developing ambidexterity, as well as their outcomes. Then, we break down the first category into three sub-categories, according to the employee level within an organization, namely, employees, managers, and leaders. We also develop three sub-categories for the structures and procedures category as well (team, project and organizational), based on the boundary that the characteristics take place within the organization.

Based on this, we first present an organizing framework of the researched area (see Figure 5) that provides the basic elements of the extant literature and guides the synthesis section towards developing a more comprehensive, multidisciplinary, and multidimensional framework of micro-level ambidexterity and MNEs (figures 6 and 7).

"Insert Figure 5 about here"

\section{Human Capital Characteristics Employees}


The first sub-category refers to antecedents of ambidexterity that relate to individual characteristics of lower level employees within an MNE. To start with, Van der Borgh and Schepers (2014) found, among others, the positive impact of a salesperson's degree of task autonomy, in terms of how to allocate time and effort, on employee ambidexterity. The authors also found that employee ambidexterity relates positively with employee sales performance on new products, and consequently, on a salesperson net profit. Continuing, Kostopoulos et al. (2015) found that some of the elements of intellectual capital have a positive or negative association with business unit ambidexterity. In particular, unit human capital, which refers to knowledge, abilities and skills that employees have, as well as social capital, which incorporates the pattern of employees' relationship networks and ties, have a positive impact on business unit ambidexterity. However, the authors also found that organizational capital, which refers to established norms, routines and structures with the purpose of developing a systematic documentation of knowledge and enhanced usage repetition of the documented knowledge, is negatively related with unit ambidexterity. On the contrary, Fu et al. (2016) also examined intellectual and its impact on business unit ambidexterity but they found contradicting results in relation to Kostopoulos et al. (2015) findings. In particular, the authors found that all intellectual capital elements (human social and organizational capital) have a positive relationship with the development of a business unit ambidexterity. A possible explanation for these contradicting results is the contextual role of culture in terms of individualistic and collectivistic societies, as the authors conducted a comparative study between China and Ireland and observed that the findings are mixed across the two countries. Thus, future studies need to investigate further the contextual role of culture and its impact on various factors that may enable not only business unit ambidexterity, but also, employee and leadership ambidexterity. Continuing, Kao et al. (2016) examined the impact of intrinsic motivation on a sample of 205 flight attendants of an MNE and found that it positively relates 
to the development of ambidexterity among employees, which in turn, enhances service performance. The authors also examined various moderating factors on this relationship and their results showed that emotional intelligence plays a positive moderating role whereas extrinsic reward and proactive personality are negative moderators. On a different setting, Yan et al. (2016) explored the role of organizational learning at multiple levels of analysis, either separately or by combining organizational learning at various levels, and its impact on the development of various forms of ambidexterity at the organization as a whole. Their findings showed that, organizational learning at the individual and team level positively relate to the development of technological ambidexterity. Also, when organizational learning is applied at the individual and inter-organizational levels it enhances the development of market-oriented ambidexterity. Finally, Josserand et al. (2017) examined the impact of individual (employee level) network connections (social capital) on business unit ambidexterity. By conducting 33 interviews with participants from a global commodity firm, they found that the exploitation and exploration of external networks (network connections) by employees that includes both strong and week ties, relate positively to the development of business unit ambidexterity as they provide access to knowledge that is translated into possible opportunities for exploitation and exploration. Adding to this, the authors also found that three managerial conditions act as positive moderators on the relationship between employee social capital (network ties) and the development of business unit ambidexterity: 1) managerial autonomy, 2) the development of a network culture that promotes collaboration, sharing of information and client centricity stimulating the development of individual networks, and 3) the development of organized network redundancies. In other words, employees create their own client networks by utilizing existing contacts or developing new ones, In turn, this action promotes the development of multiple contacts with external stakeholders on various functions and levels of hierarchy.

\section{Managers}


The second sub-category refers to antecedents of ambidexterity development at MNEs, that relate to individual characteristics of middle level managers. Towards this direction, Mom et al. (2007) found that the way a manager acquires information and knowledge (top-down, bottom up, or horizontal), also called knowledge inflows, has a positive impact on the development of ambidextrous managers. By drawing on a sample of 104 managers from an international electronics company, the authors found that knowledge acquired by lower level employees (bottom-up knowledge inflows) affects positively the development of a manager's exploration activity. The same holds if the knowledge is acquired by peers at the same hierarchical level (horizontal knowledge inflows), whereas knowledge acquired by employees or units that belong to a higher level of the organizational hierarchy enhances the development of a manager's exploitation activity. On a different note, Mom et al. (2009) found that the development of social relationships by participating in cross-functional connectedness and interfaces with other members of the organization enhances the development of ambidextrous managers. In a similar vein, Turner et al. (2013) and Turner \& Lee-Kelley (2013) examined the role of managerial intellectual (human, social, organizational) capital on the development of project level ambidexterity. Their findings showed a positive relationship between the two constructs. Adding to this, Turner et al. (2013) examined various other factors on the development of project-level ambidexterity. Their findings showed that integration, roleexpansion gap-filling, setting the tone and buffering managerial practices have a positive impact on project ambidexterity, which in turn enhances project performance. Finally yet importantly, Van der Borgh and Schepers (2014) showed that a manager's ambidextrous selling orientation has a positive impact on the development of employees' task autonomy, which in turn enhances employee sales performance. Adding to this, the authors found that when the information that managers provide to employees in order to direct their sales performance is 
minimal (little managerial feedback), as well as older salespeople act as positive moderators on the relationship between ambidextrous managers and salesperson performance.

\section{Leaders and Top-Management Team members}

The third sub-category refers to antecedents of ambidexterity development at MNEs that relate to individual characteristics of TMT members and leaders. We identified three studies that focus on this sub-category. To start with, Atuahene-Gima and Murray (2007) examined the behavior of TMT members from 179 multinational firms operating in China and found a positive relationship between various social capital dimensions of TMT members' behavior and the development of ambidextrous leaders. In particular, the findings showed that intraindustry ties (network ties with executives of other organizations that operate within the actor's same sector/industry), as well as the power of TMT members enhance both exploration and exploitation, whereas extraindustry ties (connections with other executives that belong to companies operating in other than the actor's industry) enhance exploration. Adding to this, trust enhances exploitation whereas solidarity and strategic consensus relate positively to exploration activities. Moreover, their results also showed that the development of organizational ambidexterity is achieved only if there is a balance between exploration and exploitation activities. Continuing, by drawing on a sample of 453 participants in 71 work teams of a large multinational organization, Nemanich \& Vera (2009) found that transformational leadership behaviors characterized by intellectual stimulation, idealized influence, individual consideration and inspirational motivation, have a positive impact on (contextual) ambidexterity at the team level. On a different note, Child et al. (2017) found that one of the main business models through which SMEs internationalize is the ambidextrous business model (organizational ambidexterity). Adding to this, the authors found that, when the decision-maker/ leader of an SME has previous international experience, the possibility of an SME to apply the ambidextrous model is enhanced. 


\section{Structures \& Procedures Team}

The first sub-category refers to antecedents of ambidexterity development at MNEs that relate to structural characteristics and procedures at the team level within an organization. Towards this direction, Yan et al. 2016 found that when organizational learning is applied at both the team and organizational level it enables the development of management-oriented ambidexterity at the organization. Continuing, by drawing on quantitative data from a large multinational enterprise, Haas (2010) identified the positive effect of external knowledge and team autonomy on team operational and strategic effectiveness through the development of team ambidexterity. In particular, autonomy provides teams with the basis to engage in exploitation activities, whereas external knowledge provides them with the possibility to explore new opportunities and approaches. Moreover, the authors found that high task pressure, the scarcity of knowledge content, task uncertainty, and when knowledge sources come from outside the organizational boundaries, act as positive moderators on the autonomy-knowledge interaction effect. Lastly, Revilla and Rodríguez (2011), examined the relationship between team vision and team effectiveness on new product development performance at the organization. Their findings showed that team ambidexterity mediates this relationship. Adding to this, the findings also showed that high ambidexterity, in terms of high levels of both exploration and exploitation moderate the relationship between team vision and team effectiveness.

\section{Project}

The second sub-category refers to antecedents of ambidexterity development at MNEs that relate to structural characteristics and procedures at the project level within an organization. Within this sub-category, we identified only one study, thus making it the less researched subcategory within this research path. Towards this research direction, Bröring and Herzog (2008) focused on how ambidexterity at the project level is achieved in large multinationals. By 
undertaking an in-depth exploration on the topic based on a qualitative research approach with an international firm operating in the Information Technology sector, their findings showed that several project level components, as well as processes, enable the development of project level ambidexterity. In particular, their findings showed that the combination of external and internal research and development activities in a project setting, the enhanced degree of project openness in terms of open and closed innovation, as well as the composition of a project with employees coming from different business units, all contribute to the development of project level ambidexterity.

\section{Organizational}

The third and last sub-category refers to antecedents of ambidexterity development at MNEs that relate to structural characteristics and procedures that take place at the organization as a whole and have an impact on the micro-level ambidexterity development. To start with, Bröring and Herzog (2008) found that, in order to achieve ambidexterity at the project level, three organizational factors play an important role: first, organizations need to have flexible settings that allow the movement between exploration and exploitation; second, organizations need to bring inside the organizational boundaries new knowledge through the collaborations with their partners/ external stakeholders, including, customers, universities, and research institutes, and; third, the exchange of scientists between partners, enables project house ambidexterity. In turn, they found that ambidexterity at the project level enhances new product development success. Continuing, in the context of an acquisition by MNEs, Nemanich and Vera (2009) found that the development of a learning culture within the organization, including, the participation in decision making, psychological safety, and openness to various and diverse opinions, enhance the development of team ambidexterity. Furthermore, Mom et al. (2009) found that when organizational procedures promote a manager's decision-making authority, the development of managerial ambidexterity is enhanced. Adding to this, Fiset and 
Dostaler (2013) empirically showed that a supportive organizational context is positively related with the development of contextual ambidexterity in a project level, which, in turn, enhances the development of schedule adherence performance.

Moreover, the development of new managerial positions within a multinational organization, namely, higher-level intermediary', enhances the coordination across geographical and functional boundaries within the entire organizational context, by providing access at all organizational members to various knowledge sources, thus, providing knowledge exchange opportunities. In other words, higher-level intermediaries act as an ambidextrous linkage between informal and formal knowledge search and transfer mechanisms. In turn, the effectiveness of knowledge transfer has a positive impact on the company's ability to exploit its knowledge base and enhance organizational performance (Patriotta et al. 2013). Continuing, according to Kostopoulos et al. (2013) the development of organizational high-performance human resource practices enhance the development of an organizational context that enables employees of the various business units with the ability, motivation, and opportunity to perform and utilize diverse knowledge assets, and includes flexible assignments and generalized skills training, as well as broad employee career paths and job descriptions. Adding to this, such human resource practices moderate the positive relationship between employee ambidexterity and unit ambidexterity, as well as the relationship between unit ambidexterity and unit performance, whereas it mitigates the negative relationship between organizational capital and business unit ambidexterity. On a different note, Birkinshaw et al. (2016) focused on understanding how organizations manage strategic dualities in practice, through a detailed longitudinal analysis of a multinational organization, in real time, as it was challenged with the integration/ local responsiveness duality (from a single focus in Europe to a dual European and Asian focus, through the development of dual headquarters). The results showed three mechanisms for establishing contextual ambidexterity at the employee level (shifting 
employee's singular focus into a dual focus), and subsequently, to successfully manage a strategic duality. First, the counterweight logic which emphasizes an alternative strategic imperative, the hybrid engine logic which enhances the development of a balanced perspective (the creation of structures and systems that support equal focus at two points), and the flywheel logic which creates enhanced ownership of the integrated view at lower (employee) levels within the organization. In turn, this transformation, which relates to the development of contextual ambidexterity at the employee level, enhances the process of managing a strategic duality in MNEs.

Continuing, Yan et al. (2016) empirically showed that organizational learning at the organizational level enhances the development of management-oriented ambidexterity, whereas Gebauer et al. (2017) found that when organizations assign job responsibilities that balance the exploration and exploitation activities of individual entrepreneurs, the development of organizational ambidexterity is enhanced, which in turn positively affects the development of a business model innovation. On a different note, Bresciani et al. 2018 investigated MNEs operating through alliances in the context of Smart Cities, and they found that knowledge management capabilities, which refers to knowledge creation and knowledge integration, combined with information and communication technologies capabilities (ICTs), which relates to ICT internal use, collaboration, and communication, relate positively with the enhancement of ambidexterity performance at the project portfolio level. In conclusion, the last study identified in this sub-category focused on the impact of various organizational level antecedents for developing ambidexterity at an MNE setting. In particular, Snehvrat and Dutta (2018) identified three organizational antecedents that relate positively to the development of team ambidexterity: 1) ostensive metaroutines that include lean processes and structures, esourcing, voice of customer, partnership strategies and commonality, and; 2) performative metaroutines which include leadership exclusive contracts, the need to complement each other, 
and creative recombination. Based on these metaroutines, decisions are made across various levels, whereas the owner of these metaroutines in the top management. Adding to this, employees have clear roles and responsibilities whereas coordinators focus on inter group consistency. Finally, in terms of employee' skills, a combination of coordinators and specialists exists. In turn, the authors found that team ambidexterity has a positive impact on new product development performance.

\section{A conceptual framework}

We now synthesize the review findings in the form of an integrative, multi-dimensional, and preliminary conceptual framework presented in Figures 6 (Part 1) and 7 (Part 2). In the first part, our framework starts with a differentiation between the Human capital characteristics and Structures \& Procedures categories of ambidexterity antecedents in an MNE setting. Next, each category is further divided in to three sub-categories respectively, based on the antecedent level, on either human capital characteristics or structural boundaries and procedures in an organization. The framework continues with the identified antecedents that relate to each subcategory. For each antecedent we denote the relationship with an $\mathrm{R}$ and a number next to it, in order to have the source (see Figure 7) and a relationship continuum as the framework continues with the ambidexterity outcomes on various levels of analysis. Next, our framework illustrates the outcomes of these antecedents on the individual, team, project, and business unit level. We name each outcome with the letter O plus a number (i.e., O1) and we state the sequence of relationships. Thus, for example, Schedule adherence performance states an O7: R10 relationship. This means that the R10 antecedent, which relates to supportive organizational context, has a positive impact on $\mathrm{O} 7$ (Project ambidexterity) which is which in turn, enhances schedule adherence performance. Next, our framework illustrates the various outcomes on the organization as a whole. Here again, we clarify the relationship path for each outcome. The second part of our framework (Figure 7) presents the moderating, conditional 
and contextual factors that affect the various relationships presented in Part 1, as well as the literature sources for each of these relationships.

"Insert Figure 6 about here"

"Insert Figure 7 about here"

Our framework is not static and fulfilling, but rather it captures the current state of extant literature on the development of ambidexterity in MNEs, from a micro-foundational perspective. Thus, it operates as a guiding tool to which future scholars can add other dependent and independent variables, as well as moderators, and contextual factors. Moreover, our framework provides an understanding of the multidisciplinary nature of the reviewed topic, as well as the interplay between the various levels of analysis, the interrelationships between micro-level variables with macro-level outcomes and vice-versa, and the complex nature of ambidexterity development in an MNE context. The integration that our framework offered in Figures 7 and 8 can provide the basis for future micro-level ambidexterity research within MNEs, in a more systematic way.

\section{Contributions}

Our study makes the following five contributions to scholarly research and management practice. First, by focusing on the micro-foundational perspective of ambidexterity research in the context of MNEs, this study advances our understanding of the complexity and importance of this research domain in the wider international business and ambidexterity research and provides the ground for bridging these two distinct disciplines. Second, to our knowledge, we offer the first systematic review of extant research on the micro-foundations of ambidexterity and MNEs, which maps extant literature and its various research paths about the subject, developed in a diverse theoretical and contextual setting, underlining their focus, main concepts and theories, as well as their findings. Third, we develop a comprehensive multi-dimensional 
and multi-disciplinary framework that organizes extant literature and provides a better understanding within and across multiple levels of analysis. Fourth, one of the objectives of this systematic and critical review was the identification of important research areas that provide us with the opportunity to improve our knowledge of micro-lever ambidexterity research in MNEs. Thus, an additional contribution of this study is the identification of various knowledge gaps, emerging themes and limitations of extant research, through which we offer a future research agenda that focuses on a multi-level and multi-disciplinary approach and aims on providing a better understanding of the micro-foundations of ambidexterity in the context of MNEs. Finally, our study provides a guiding tool for managers and executives in MNEs in developing ambidexterity within their organization to capture its various outcomes.

\section{Limitations and Additional Recommendations for future research}

Like any other systematic review, this study had limitations as well. The first limitation is that the findings from this systematic review were identified from three scientific databases, with a specific keyword search formula. We recognize that every keyword search has its limitations, which could result in failing to capture some relevant papers on the review topic (Nofal et al. 2018; Crossan and Apaydin, 2010); however, we believe that a different keyword selection would not have altered our results, as we developed our keyword search based on a careful examination of the keywords applied in earlier reviews from top journals. Despite this, future researchers could explore related literature from other databases with the use of other keyword combinations. Second, our review is limited to the micro-foundational perspective of ambidexterity in MNEs. Thus, we have excluded several articles that focus on the macro-level perspective of ambidexterity in the context of MNEs. Therefore, future research could provide

a systematic review and a conceptual framework that includes both micro and macro perspectives of ambidexterity. 
Despite these limitations, our review offered various future research directions when analyzing and synthesizing the data. Apart from these future directions, we identified an additional three avenues that provide fruitful future research, which we report here. First, according to the analysis of the review findings, there is limited research on the micro-foundational perspective of ambidexterity as regards to the structural elements and procedures at the project and team level of an MNE. Thus, future research could further investigate either variables that relate to the content, structure, or processes that exist within a team or a project level of MNEs, and their impact on developing ambidexterity at various levels of analysis. Second, I the context of an MNE, organizational units (i.e., subsidiaries) could belong to various geographical contexts. Thus, employees of such organizational units may have different values, norms, and knowledge base from members of their organizational units within the same MNE. Moreover, it is possible that each organizational unit operates in different markets and has different networks with external stakeholders. Therefore, future research could potentially examine the role of culture, religion, and other country specific demographic characteristics on the various micro-level antecedents of ambidexterity at the individual level on various hierarchical members of an MNE. In addition, future research could also examine the nature of the relationships and engagement with various external stakeholders in different geographical contexts, and the ways MNEs could manage such a diverse network for promoting ambidexterity at the whole organization. In conclusion, Junni et al. (2015) stated that an important area for future research in ambidexterity literature is to investigate the combined effects of ambidexterity antecedents, as well as the interrelationships between them. Based on the findings of this review, microlevel ambidexterity research focusing on MNEs also lacks from such studies, something that is imperative to be done, as it will advance our knowledge on this research stream.

\section{Conclusion}


Two reasons motivated this systematic review. First, an increasing research interest on the micro-foundational aspect of ambidexterity shows that its micro-level antecedents are influential in explaining the development of ambidexterity on multiple levels and its consequent outcomes within an MNE. Second, to our knowledge, no systematic review of extant research on the micro-foundations of ambidexterity and MNEs existed. Consequently, we sought to contribute to an understanding of ambidexterity from a micro-foundational point of view within the context MNEs, by conducting a systematic analysis of extant literature published on this topic in peer-reviewed journal articles from various fields, including, among other, international business, innovation, strategy, general management, marketing. We developed a comprehensive, multidisciplinary, and multidimensional framework that organizes existing literature within and across various disciplines and multiple levels of analysis. By synthesizing and critically evaluating existing research on micro-level ambidexterity and MNEs across multiple disciplines and levels, we hope to have contributed to a better understanding of the topic and to have enhanced cross-fertilization of theories and concepts into new research paths that will expand the boundaries of this emerging research stream.

\section{REFERENCES}

Abell, P., Felin, T., \& Foss, N. (2008). Building microfoundations for the routines, capabilities, and performance links. Managerial and Decision Economics, 29, 489-502.

Aguinis, H., \& Glavas, A. (2012). What we know and don't know about corporate social responsibility: A review and research agenda. Journal of Management, 38(4), 932-968.

Ahuja, G., Soda, G., \& Zaheer, A. (2012). The genesis and dynamics of organizational networks. Organization Science, 23(2), 434-448.

Alzahrani, L., Al-Karaghouli, W., \& Weerakkody, V. (2017). Analysing the critical factors influencing trust in e-government adoption from citizens' perspective: A systematic review and a conceptual framework. International Business Review, 26(1), 164-175. 
Atuahene-Gima, K., \& Murray, J. Y. (2007). Exploratory and exploitative learning in new product development: A social capital perspective on new technology ventures in China. Journal of International Marketing, 15(02), 1-29.

Bapuji, H., Hora, M., \& Saeed, A. M. (2012). Intentions, intermediaries, and interaction: Examining the emergence of routines. Journal of Management Studies, 49, 1586- 1607.

Baron, S., Warnaby, G., \& Hunter-Jones, P. (2014). Service (s) marketing research: developments and directions. International Journal of Management Reviews, 16(2), 150-171.

Birkinshaw, J., Crilly, D., Bouquet, C., \& Lee, S. Y. (2016). How do firms manage strategic dualities? A process perspective. Academy of Management Discoveries, 2(1), 51-78.

Boiral, O., Guillaumie, L., Heras-Saizarbitoria, I., \& Tayo Tene, C. V. (2018). Adoption and outcomes of ISO 14001: a systematic review. International Journal of Management Reviews, 20(2), 411-432.

Bresciani, S., Ferraris, A., \& Del Giudice, M. (2018). The management of organizational ambidexterity through alliances in a new context of analysis: Internet of Things (IoT) smart city projects. Technological Forecasting and Social Change, 136, 331-338.

Bridoux, F., \& Stoelhorst, J. (2014). Microfoundationsfor stakeholder theory: Managing stakeholders with heterogeneous motives. Strategic Management Journal, 35, 107-125.

Bröring, S., \& Herzog, P. (2008). Organising new business development: open innovation at Degussa. European Journal of Innovation Management, 11(3), 330-348.

Chebbi, H., Yahiaoui, D., Vrontis, D., \& Thrassou, A. (2015). Building multiunit ambidextrous organizations-A transformative framework. Human Resource Management, 54(S1), s155-s177.

Child, J., Hsieh, L., Elbanna, S., Karmowska, J., Marinova, S., Puthusserry, P., ... \& Zhang, Y. (2017). SME international business models: The role of context and experience. Journal of World Business, 52(5), 664-679.

Christoffersen, J. (2013). A review of antecedents of international strategic alliance performance: synthesized evidence and new directions for core constructs. International Journal of Management Reviews, 15(1), 66-85.

Christofi, M., Leonidou, E., \& Vrontis, D. (2017). Marketing research on mergers and acquisitions: a systematic review and future directions. International Marketing Review, 34(5), 629-651. 
Crossan, M. M., \& Apaydin, M. (2010). A multi-dimensional framework of organizational innovation: A systematic review of the literature. Journal of management studies, 47(6), 1154-1191.

De Menezes, L. M., \& Kelliher, C. (2011). Flexible working and performance: A systematic review of the evidence for a business case. International Journal of Management Reviews, 13(4), 452-474.

Dezi, L., Ferraris, A., Vrontis, D., Papa, A. (2019). "The role of external embeddedness and knowledge management as antecedents of ambidexterity and performances in Italian SMEs", IEEE Transactions on Engineering Management, forthcoming DOI: https://doi.org/10.1016/j.jbusres.2018.12.010

Devinney, T. (2013). Is microfoundational thinking critical to management thought and practice? Academy of Management Perspectives, 27, 81-84.

Eisenhardt, K., Furr, N. R., \& Bingham, C. B. (2010). Microfoundations of performance: Balancing efficiency and flexibility in dynamic environments. Organization Science, 21, $1263-1273$.

Felin, T., \& Foss, N. (2005). Strategic organization: A field in search of micro-foundations. Strategic Organization, 3(4), 441-455.

Felin, T., Foss, N. J., \& Ployhart, R. E. (2015). The microfoundations movement in strategy and organization theory. The Academy of Management Annals, 9(1), 575-632.

Felin, T., Foss, N., Heimeriks, K., \& Madsen, T. (2012). Microfoundations of routines and capabilities: Individuals, processes, and structure. Journal of Management Studies, 49, 13511374.

Ferraris, A., Erhardt, N., Bresciani, S. (2019). “Ambidextrous Work in Smart City Project Alliances: Unpacking the Role of Human Resource Management Systems", International Journal of Human Resource Management, Vol. 30, No. 4, pp. 680-701. DOI: 10.1080/09585192.2017.1291530

Ferraris A., Monge, F., Mueller, (2018) "Ambidextrous IT capabilities and business process performance: An empirical analysis", Business Process Management Journal, Vol. 24 No. 5, pp. 1077-1090.

Fiset, J., \& Dostaler, I. (2013). Combining old and new tricks: ambidexterity in aerospace design and integration teams. Team Performance Management, 19(7/8), 314-330.

Foss, N. J. (2011). Why micro-foundations for resource-based theory are needed and what they may look like. Journal of Management, 37, 1413-1428. 
Foss, N. J., \& Lindenberg, S. (2013). Micro-foundations for strategy: A goal-framing perspective on the drivers of value creation. Academy of Management Perspectives, 27, 85102.

Fu, N., Ma, Q., Bosak, J., \& Flood, P. (2016). Intellectual capital and organizational ambidexterity in Chinese and Irish professional service firms. Journal of Organizational Effectiveness: People and Performance, 3(2), 94-114.

Gavetti, G. (2005). Cognition and hierarchy: Rethinking the microfoundations of capabilities' development. Organization Science, 16, 599-617.

Gebauer, H., Saul, C. J., \& Haldimann, M. (2017). Business model innovation in base of the pyramid markets. Journal of Business Strategy, 38(4), 38-46.

George, G., Corbishley, C., Khayesi, J. N., Haas, M. R., \& Tihanyi, L. (2016). Bringing Africa in: Promising directions for management research. Academy of Management Journal, 59(2), 377-393.

Geppert, M., \& Dörrenbächer, C. (2014). Politics and power within multinational corporations: Mainstream studies, emerging critical approaches and suggestions for future research. International Journal of Management Reviews, 16(2), 226-244.

Grigoriou, K., \& Rothaermel, F. (2014). Structural microfoundations of innovation: The role of relational stars. Journal of Management, 40(2), 586-615.

Haas, M. R. (2010). The double-edged swords of autonomy and external knowledge: Analyzing team effectiveness in a multinational organization. Academy of Management Journal, 53(5), 989-1008.

Han, M. (2007). Achieving superior internationalization through strategic ambidexterity. Journal of Enterprising Culture, 15(01), 43-77.

Horwitz, F. (2015). Human resources management in multinational companies in Africa: a systematic literature review. The International Journal of Human Resource Management, 26(21), 2786-2809.

Hughes, M., Martin, S. L., Morgan, R. E., \& Robson, M. J. (2010). Realizing product-market advantage in high-technology international new ventures: The mediating role of ambidextrous innovation. Journal of International Marketing, 18(4), 1-21.

Jones, O. and Gatrell, C. (2014). Editorial: the future of writing and reviewing for IJMR. International Journal of Management Reviews, 16, pp. 249-264. 
Josserand, E., Schmitt, A., \& Borzillo, S. (2017). Balancing present needs and future options: how employees leverage social networks with clients. Journal of business strategy, 38(1), 1421.

Junni, P., Sarala, R. M., Tarba, S. Y., Liu, Y., \& Cooper, C. L. (2015). Guest editors' introduction: The role of human resources and organizational factors in ambidexterity. Human Resource Management, 54(S1), s1-s28.

Junni, P., Sarala, R., Taras, V., \& Tarba, S. (2013). Organizational ambidexterity and performance: A meta-analysis. Academy of Management Perspectives, 27(4), 299-312.

Kao, Y. L., \& Chen, C. F. (2016). Antecedents, consequences and moderators of ambidextrous behaviours among frontline employees. Management Decision, 54(8), 18461860.

Kemper, J., Schilke, O., Brettel, M. (2013). Social capital as a microlevel origin of organizational capabilities. Journal of Product Innovation Management, 30(3), 589- 603.

Kostopoulos, K. C., Bozionelos, N., \& Syrigos, E. (2015). Ambidexterity and unit performance: Intellectual capital antecedents and cross-level moderating effects of human resource practices. Human Resource Management, 54(S1), s111-s132.

Leonidou, E., Christofi, M., Vrontis, D., \& Thrassou, A. (2018). An integrative framework of stakeholder engagement for innovation management and entrepreneurship development. Journal of Business Research.

Li, X., Quan, R., Stoian, M. C., \& Azar, G. (2018). Do MNEs from developed and emerging economies differ in their location choice of FDI? A 36-year review. International Business Review.

Lindenberg, S., \& Foss, N. (2011). Managing joint production motivation: The role of goal framing and governance mechanisms. Academy of Management Review, 36(3), 500-525.

Lippman, S. A., \& Rumelt, R. (2003a). The payments perspective: Micro-foundations of resource analysis. Strategic Management Journal, 24(10), 903-927

Loch, C., Segupta, K., \& Ahmad, M. (2013). The microevolution of routines: How problem solving and social preferences interact. Organizational Science, 24, 99- 115.

López-Duarte, C., Vidal-Suárez, M. M., \& González-Díaz, B. (2016). International business and national culture: a literature review and research agenda. International Journal of Management Reviews, 18(4), 397-416. 
Luger, J., Raisch, S., \& Schimmer, M. (2018). Dynamic Balancing of Exploration and Exploitation: The Contingent Benefits of Ambidexterity. Organization Science, 29(3), 449470 .

Mallett, R., Hagen-Zanker, J., Slater, R. and Duvendack, M. (2012). The benefits and challenges of using systematic reviews in international development research. Journal of Development Effectiveness, 4, pp. 445-455.

Miller, K., Pentland, B., \& Choi, S. (2014). The role of transactive memory in the formation of organizational routines. Strategic Organization, 12, 109-133.

Mom, T. J., Van Den Bosch, F. A., \& Volberda, H. W. (2007). Investigating managers' exploration and exploitation activities: The influence of top-down, bottom-up, and horizontal knowledge inflows. Journal of management studies, 44(6), 910-931.

Mom, T. J., Van Den Bosch, F. A., \& Volberda, H. W. (2009). Understanding variation in managers' ambidexterity: Investigating direct and interaction effects of formal structural and personal coordination mechanisms. Organization Science, 20(4), 812-828.

Nadeem, S., Raza, M., Kayani, N., Aziz, A., \& Nayab, D. (2018). Examining cross-cultural compatibility of high performance work practices. International Business Review, 27(3), 563583.

Nemanich, L. A., \& Vera, D. (2009). Transformational leadership and ambidexterity in the context of an acquisition. The Leadership Quarterly, 20(1), 19-33.

Nofal, A. M., Nicolaou, N., Symeonidou, N., \& Shane, S. (2018). Biology and Management: A Review, Critique, and Research Agenda. Journal of Management, 44(1), 7-31.

Paruchuri, S., \& Eisenman, M. (2012). Microfoundations of firm R\&D capabilities: A study of inventor networks in a merger. Journal of Management Studies, 49, 1509-1535.

Patriotta, G., Castellano, A., \& Wright, M. (2013). Coordinating knowledge transfer: Global managers as higher-level intermediaries. Journal of World Business, 48(4), 515-526.

Pisani, N., Kourula, A., Kolk, A., \& Meijer, R. (2017). How global is international CSR research? Insights and recommendations from a systematic review. Journal of World Business, 52(5), 591-614.

Pittaway, L., Robertson, M., Munir, K., Denyer, D., \& Neely, A. (2004). Networking and innovation: a systematic review of the evidence. International journal of management reviews, 5(3-4), 137-168. 
Podsakoff, P.M., MacKenzie, S.B., Bacharach, D.G. and Podsakoff, N.P. (2005). The influence of management journals in the 1980s and 1990s. Strategic Management Journal, 26, pp. 473-488.

Raisch S, Birkinshaw J (2008) Organizational ambidexterity: Antecedents, outcomes, and moderators. J. Management 34(3): 375-409.

Rajwani, T., \& Liedong, T. A. (2015). Political activity and firm performance within nonmarket research: A review and international comparative assessment. Journal of World Business, 50(2), 273-283.

Rao-Nicholson, R., Khan, Z., Akhtar, P., \& Merchant, H. (2016). The impact of leadership on organizational ambidexterity and employee psychological safety in the global acquisitions of emerging market multinationals. The International Journal of Human Resource Management, 27(20), 2461-2487.

Rashman, L., Withers, E., \& Hartley, J. (2009). Organizational learning and knowledge in public service organizations: A systematic review of the literature. International Journal of Management Reviews, 11(4), 463-494.

Revilla, E., \& Rodríguez, B. (2011). Team vision in product development: How knowledge strategy matters. Technovation, 31(2-3), 118-127.

Rogan, M., \& Mors, M. L. (2014). A network perspective on individual-level ambidexterity in organizations. Organization Science, 25(6), 1860-1877.

Rozen-Bakher, Z. (2018). The trade-off between synergy success and efficiency gains in M\&A strategy. EuroMed Journal of Business.

Schuler, R. S., Dowling, P. J., \& De Cieri, H. (1993). An integrative framework of strategic international human resource management. Journal of management, 19(2), 419-459.

Sefiani, Y., Davies, B. J., Bown, R., \& Kite, N. (2018). Performance of SMEs in Tangier: the interface of networking and wasta. EuroMed Journal of Business, 13(1), 20-43.

Snehvrat, S., \& Dutta, S. (2018). Multi-level ambidexterity in new product introduction at Tata Motors, India: The role of metaroutines. Journal of Organizational Effectiveness: People and Performance.

Sousa, C. M., Martínez-López, F. J., \& Coelho, F. (2008). The determinants of export performance: A review of the research in the literature between 1998 and 2005. International Journal of Management Reviews, 10(4), 343-374. 
Stumbitz, B., Lewis, S., \& Rouse, J. (2018). Maternity management in SMEs: a transdisciplinary review and research agenda. International Journal of Management Reviews, 20(2), 500-522.

Teece, D. (2007). Explicating dynamic capabilities: The nature and microfoundations of (sustainable) enterprise performance. Strategic Management Journal, 28, 1319- 1350.

Terjesen, S., Hessels, J., \& Li, D. (2016). Comparative international entrepreneurship: A review and research agenda. Journal of Management, 42(1), 299-344.Thornton, P. H., Ocasio, W., \& Lounsbury, M. (2012). The institutional logics perspective: A new approach to culture, structure and process. Oxford: Oxford University Press.

Tranfield, D., Denyer, D. and Smart, P. (2003). Towards a methodology for developing evidence-informed management knowledge by means of systematic review. British Journal of Management, 14, pp. 207-222.

Turner, N., \& Lee-Kelley, L. (2013). Unpacking the theory on ambidexterity: An illustrative case on the managerial architectures, mechanisms and dynamics. Management Learning, 44(2), 179-196.

Turner, N., Maylor, H., \& Swart, J. (2013). Ambidexterity in managing business projects-an intellectual capital perspective. International Journal of Managing Projects in Business, 6(2), 379-389.

Turner, N., Swart, J., \& Maylor, H. (2013). Mechanisms for managing ambidexterity: A review and research agenda. International Journal of Management Reviews, 15(3), 317-332.

Vahlne, J. E., \& Jonsson, A. (2017). Ambidexterity as a dynamic capability in the globalization of the multinational business enterprise (MBE): Case studies of AB Volvo and IKEA. International Business Review, 26(1), 57-70.

Van der Borgh, M., \& Schepers, J. J. (2014). Do retailers really profit from ambidextrous managers? The impact of frontline mechanisms on new and existing product selling performance. Journal of Product Innovation Management, 31(4), 710-727.

Volberda, H., Foss, N., \& Lyles, M. (2010). Absorbing the concept of absorptive capacity: How to realize its potential in the organization field. Organization Science, 21(4), 931-951.

Vrontis, D., \& Christofi, M. (2019). R\&D internationalization and innovation: A systematic review, integrative framework and future research directions. Journal of Business Research.

Vrontis, D., Thrassou, A., Santoro, G., \& Papa, A. (2017). Ambidexterity, external knowledge and performance in knowledge-intensive firms. The Journal of Technology Transfer, 42(2), 374-388. 
Wang, C.L. and Chugh, H. (2014). Entrepreneurial learning: past research and future challenges. International Journal of Management Reviews, 16, pp. 24-61.

Winter, S. G. (2011). Problems at the foundation? Comments on Felin and Foss. Journal of Institutional Economics, 7, 257-277.

Xiao, S. H., \& Nicholson, M. (2013). A multidisciplinary cognitive behavioural framework of impulse buying: A systematic review of the literature. International Journal of Management Reviews, 15(3), 333-356.

Yan, M., Yu, Y., \& Dong, X. (2016). Contributive roles of multilevel organizational learning for the evolution of organizational ambidexterity. Information Technology \& People, 29(3), 647-667.

Yang, M., \& Gabrielsson, P. (2017). Entrepreneurial marketing of international high-tech business-to-business new ventures: A decision-making process perspective. Industrial Marketing Management, 64, 147-160.

Yin, R. K. (1994). Case Study Research: Design and Methods. London: Sage.

Zhou, Y., Lu, L., \& Chang, X. (2016). Averting risk or embracing opportunity? Exploring the impact of ambidextrous capabilities on innovation of Chinese firms in internationalization. Cross Cultural \& Strategic Management, 23(4), 569-589. 
Table 1: Evolutionary development of ambidexterity research on multinational corporations

\begin{tabular}{|c|c|c|c|c|c|c|c|c|c|c|c|c|c|c|c|c|c|c|c|c|c|c|c|}
\hline YEAR & AMD & AMJ & ML & JBS & IJMPB & CC\&SM & JOEP\&P & TPM & MD & IT\&P & EJIM & Tec & IBR & JWB & IMM & TF\&SC & JMS & LQ & JIM & OS & HRM & JPIM & \\
\hline 2007 & & & & & & & & & & & & & & & & & 1 & & 1 & & & & 2 \\
\hline 2008 & & & & & & & & & & & 1 & & & & & & & & & & & & 1 \\
\hline 2009 & & & & & & & & & & & & & & & & & & 1 & & 1 & & & 2 \\
\hline 2010 & & 1 & & & & & & & & & & & & & & & & & & & & & 1 \\
\hline 2011 & & & & & & & & & & & & 1 & & & & & & & & & & & 1 \\
\hline 2012 & & & & & & & & & & & & & & & & & & & & & & & $\mathbf{0}$ \\
\hline 2013 & & & 1 & & 1 & & & 1 & & & & & & 1 & & & & & & & & & 4 \\
\hline 2014 & & & & & & & & & & & & & & & & & & & & & & 1 & 1 \\
\hline 2015 & & & & & & & & & & & & & & & & & & & & & 2 & & 2 \\
\hline 2016 & 1 & & & & & 1 & 1 & & 1 & 1 & & & & & & & & & & & & & 5 \\
\hline 2017 & & & & 2 & & & & & & & & & 1 & 1 & 1 & 1 & & & & & & & 6 \\
\hline 2018 & & & & & & & 1 & & & & & & & & & & & & & & & & 1 \\
\hline Total & 1 & 1 & 1 & 2 & 1 & 1 & 2 & 1 & 1 & 1 & 1 & 1 & 1 & 2 & 1 & 1 & 1 & 1 & 1 & 1 & 2 & 1 & 26 \\
\hline
\end{tabular}

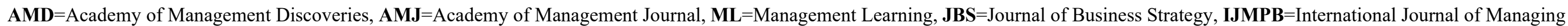

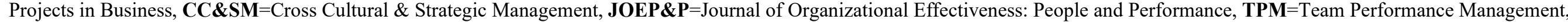

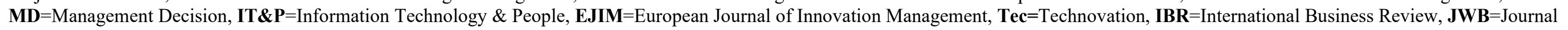

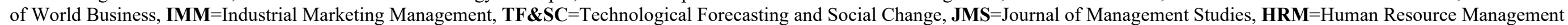
(USA), JPIM=Journal of Product Innovation Management, LQ=Leadership Quarterly, JIM=Journal of International Marketing, $\mathbf{O S}=$ Organization Science. 
Table 2: Industrial analysis of papers reviewed

\begin{tabular}{|c|c|}
\hline Citation & Industry \\
\hline Mom et al. 2007 & Electronics \\
\hline Atuahene-Gima \& Murray, 2007 & No information provided \\
\hline Bröring \& Herzog, 2008 & Chemical \\
\hline Nemanich \& Vera, 2009 & No information provided \\
\hline Mom et al. 2009 & $\begin{array}{l}\text { Multiple industries: Electronics, Financial services, } \\
\text { Accountancy and professional services, } \\
\text { Telecommunications, Chemicals }\end{array}$ \\
\hline Haas, 2010 & International development - consulting \\
\hline Revilla \& Rodríguez, 2011 & $\begin{array}{l}\text { Multiple industries: food and beverage }(20 \%) \text {, chemistry } \\
\text { and pharmaceutical }(11.3 \%) \text {, electric systems and } \\
\text { electronics }(10.1 \%) \text {, computing systems }(7.5 \%) \text {, equipment } \\
\text { manufacture }(5 \%) \text { and transport }(5 \%)\end{array}$ \\
\hline Turner \& Lee-Kelley, 2013 & Information Technology \\
\hline Turner et al. 2013 & Information Technology \\
\hline Fiset \& Dostaler, 2013 & Aerospace \\
\hline Patriotta et al. 2013 & Financial services \\
\hline Van der Borgh \& Schepers, 2014 & Retail (electronics) \\
\hline Kostopoulos et al. 2015 & High-technology industries \\
\hline Birkinshaw et al. 2016 & Information Technology \\
\hline Zhou et al. 2016 & No information provided \\
\hline Fu et al. 2016 & Accounting (Professional services) \\
\hline Kao et al. 2016 & Airline \\
\hline Yan et al. 2016 & Telecommunications \\
\hline Gebauer et al. 2017 & Water \\
\hline Josserand et al. 2017 & Chemical \\
\hline Vahlne \& Jonsson, 2017 & Multiple industries: Automotive, Furniture \\
\hline Child et al. 2017 & $\begin{array}{l}\text { Multiple industries: Clothing, software and biotechnology } \\
\text { industries }\end{array}$ \\
\hline Yang \& Gabrielsson, 2017 & High-technology \\
\hline Bresciani et al. 2017 & No information provided \\
\hline Snehvrat \& Dutta, 2018 & Automotive \\
\hline
\end{tabular}


Table 3: Authorship characteristics

\begin{tabular}{lcc} 
Authorship Characteristics & No. & $\%$ \\
\hline Number of authors & 1 & $4 \%$ \\
One & 11 & $42 \%$ \\
Two & 14 & $54 \%$ \\
Three or more & & \\
Number of countries & 16 & $62 \%$ \\
One & 6 & $23 \%$ \\
Two & 4 & $15 \%$ \\
Three or more & & \\
Number of Institutions & 9 & $35 \%$ \\
One & 9 & $35 \%$ \\
Two & 8 & $31 \%$ \\
Three or more & & \\
\hline
\end{tabular}


Table 4: Summary of selected studies

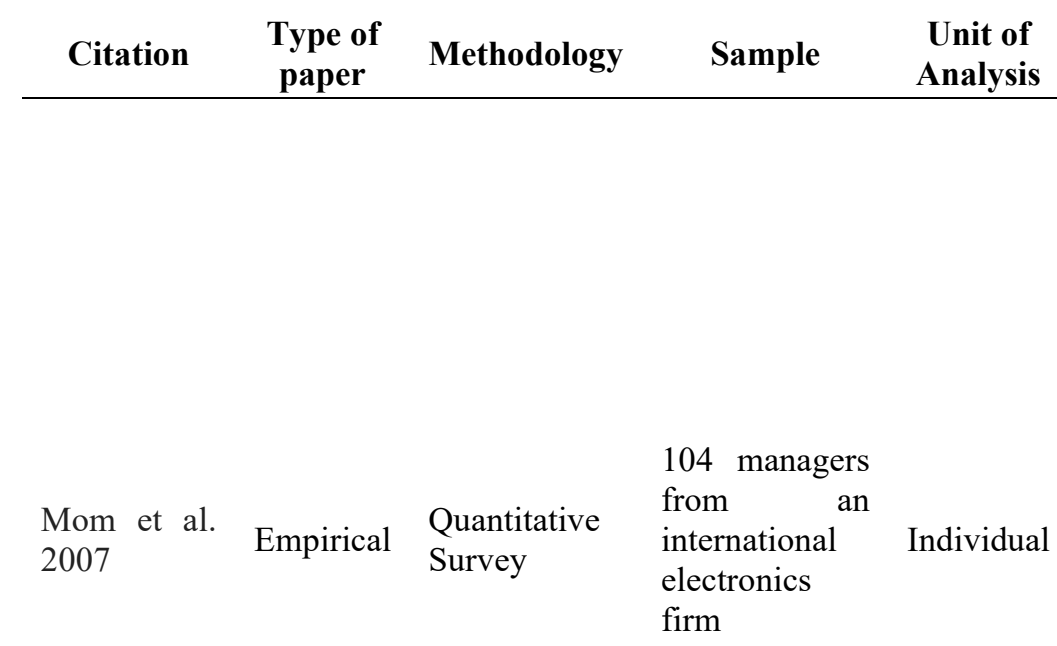

Atuahene-

$\begin{array}{llll}\begin{array}{l}\text { Gima \& } \\ \text { Murray, } \\ 2007\end{array} & \text { Empirical } & \begin{array}{l}\text { Quantitave } \\ \text { survey }\end{array} & \begin{array}{l}\text { informants } \\ \text { from 179 firms }\end{array}\end{array}$ Individual

Top-down knowledge inflows of a manager, which refers to the knowledge acquired by employees and units at higher hierarchical levels than the manager, relates positively to the managers' exploitation activities, but not to exploration activities. Bottom-up knowledge inflows of a manager (knowledge acquired by employees and units at lower hierarchical levels than the manager) and horizontal knowledge inflows (knowledge acquired by peer managers in the same organizational unit, or coming from other units at the same hierarchical level) of managers positively relate to these managers' exploration activities, while they do not relate to their exploitation activities.

Different dimensions of social capital at the TMT members' behavior are positively related to exploratory and exploitative learning. The results also support the argument that firms need a balance of exploratory and exploitative learning to enhance new product performance.

Ambidexterity at the project level, is achieved on a project house level in large multinationals, based on the following antecedents: a balanced combination of exploration and exploitation in a project house (to build on existing platform competences, which are renewed by having employees

Bröring \&

Herzog, Empirical Qualitative 2008 10interviews, observation, Project public data from different business units working jointly together; integration of internal and external R\&D; exchange of scientists between partners which brings new knowledge); flexible organizational settings that allow the transition from exploration to exploitation; enrichment of the project house with new external knowledge, which can be brought 
453

Nemanich $\begin{array}{lll}\& & \text { Vera, Empirical } & \begin{array}{l}\text { Quantitative - } \\ \text { Survey }\end{array}\end{array}$

Quantitative Survey

716 five

Mom et al 2009

Empirical questionnaires from individuals at 71 work teams

questionnaires organizations

Quantitative Survey that are included in top 25 on the Fortune Global 500 (2007)

Quantitative data from three independent sources: the organization's project evaluation

Haas, $2010 \quad$ Empirical to managers in

in through the collaboration with external partners from universities and research institutes as well as with customers; degree of openess: open and closed innovation. Ambidexterity at the projext level, enables new product development success.

In the context of an acquisition: transformational leadership behaviors characterized by individual consideration, intellectual stimulation, idealized influence and inspirational motivation, and; the development of a learning culture, characterized by openness to diverse opinions, psychological safety, and participation in decision making, positively influence (contextual) ambidexterity at the team level. Also, transformational leadership positively influence learning cultures.

Manager's decision-making authority is positively related to the ambidexterity of the manager, whereas formalization of a manager's tasks has no effect on it. A manager's participation in cross- unit, a team Team member survey $\quad(96$ teams with 485 member respondents), and archival project records functional interfaces and

Individual connectedness with other organizational members, positively relate to the development of the manager's ambidexterity. Both antecedents interract positively on the development of manager's ambidexterity.

External knowledge and team autonomy positively relate to team operational and strategic effectiveness. Autonomy allows teams to exploit their capabilities, whereas external knowledge allows them to explore new approaches and opportunities thus, team ambidexterity is enhanced. Task uncertainty, high task pressure, the scarcity of knowledge content, and when knowledge sources are non-organizational instead of organizational, all positively moderate the autonomyknowledge interaction effect. 
80

Revilla \& Rodríguez, Empirical 2011

Quantitative Survey

Turner \& Lee-Kelley, Empirical 2013

Qualitative Case study

Turner et al. 2013

Empirical Qualitative

Fiset \&

Dostaler, Empirical

Qualitative

2013 Case study

Patriotta et Empirical Qualitative questionnaires

from product Team development managers

Interviews

with $\quad 16$

participants, either individually or in groups

16 interviews with managers and 8 case studies

24 interviews at five projects teams

22 interviews with highlevel managers involved in coordinating global knowledge transfer activities at a global organization
Ambidexterity mediates the relationship between team vision and its impact on team effectiveness on product development performance. The positive effect of team vision on team effectiveness is higher (moderator) when the knowledge strategy (ambidexterity in terms of exploration and exploitation) in product development comprises higher levels of exploration and exploitation (high ambidexterity). Intellectual capital of the manager positevly relates with the development of contextual ambidexterity at the project level. The elements of intellectual capital are: human, social and organizational capital. Human capital forms the operational choices, organisational capital provides the basis through which the work is structured, and social capital enhances communication and group cohesion.

Intellectual capital of the manager (human, social and project capital instead of organizational capital) positively relate with the development of ambidexterity at the project level. Adding to this, five managerial practices that underpin the attainment of projectlevel ambidexterity are identified: buffering, gap-filling, integration, role-expansion and setting the tone. Also, ambidexterity at the project level enables project performance (delivery of project objectives).

Supportive organizational context positively affects contextual ambidexterity which in turn enhances schedule adherence performance.

The development of higher-level intermediary' as a managerial role enhances coordination across functional and geographical boundaries by making various knowledge sources available, connecting the parties to the transfer, and generating opportunities for knowledge exchange. Higher-level intermediaries act as 'ambidextrous ties' that connect informal and formal knowledge search and transfer mechanisms. In 
Van der

$\begin{array}{lll}\text { Borgh \& Empirical } & \begin{array}{l}\text { Quantitative } \\ \text { Survey }\end{array}\end{array}$ 2014

Junni et al 2015

Review

Not

applicaple

Not applicaple Multiple

Questionnaires

from 148

senior unit

employees and

Kostopoulos

Empirical

Quantitative Survey turn effective knowledge transfer enhances the company's ability to exploit its knowledge base and improve performance.

A sales manager's ambidextrous selling orientation (ambidextrous manager) has a positive relationship with the salesperson's degree of task autonomy (mediator) to decide on how to allocate time and effort. In turn, an individual's task autonomy is most likely positively related to his/her sales performance. Little managerial feedback (the information managers provide to unit employees to direct employees' sales performance) and older salespeople moderate the relationship between ambidextrous managers and salesperson performance. In turn, a salesperson's performance in selling new products relates more positively to his or her obtained sales profit (salesperson net profit). A review of 41 empirical studies identifies distinct research paths that relate to the effects of leader characteristics, employee characteristics, organizational structure, culture, social relationships, and organizational environment on ambidexterity.

Unit human (refers to knowledge, skills, and abilities employees possess) and social capital (reflects the overall pattern of members' relationship ties and networks) positively relate to unit ambidexterity. Unit organizational capital (denotes established structures, norms, and routines that serve to systematically document and preserve knowledge and subsequently encourage repeated use of it) has a negative relationship with unit ambidexterity. Organizational high-performance human resource (HPHR) practices (foster a context that provides the unit's workforce with ability, motivation, and opportunity to perform and utilize diverse knowledge assets and include: generalized skills training and flexible assignments, as well as broad job descriptions and 


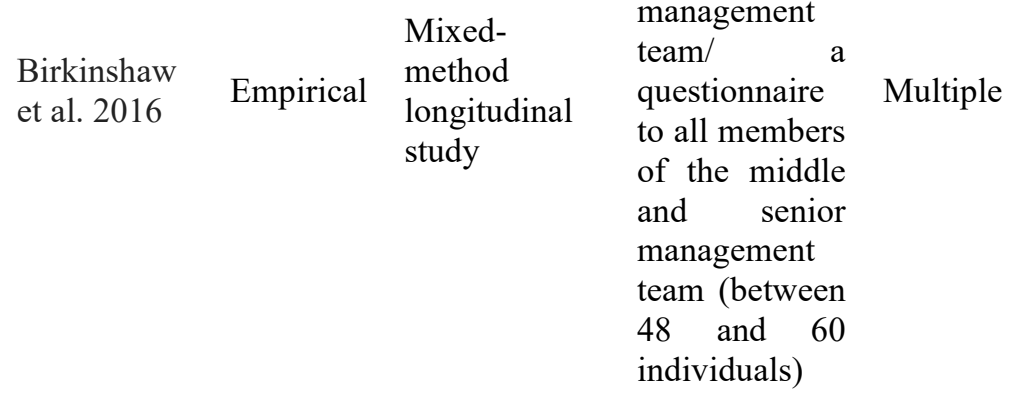
2016

Empirical

Quantitative Survey

product $\begin{array}{ll}\mathrm{Fu} \text { et al. Empirical } & \begin{array}{l}\text { Quantitative } \\ \text { Survey }\end{array}\end{array}$ managers from 189 MNEs

112 Chinese

48 interviews with the CEO and members of the senior and middle management

189 MEs and 93 Irish accounting firms career paths) amplify the former and mitigate the latter of these unitlevel effects. Organizational-level HPHR practices moderate the relationship between unit ambidexterity and unit performance.

Three mechanisms for establishing contextual ambidexterity at the employee level, which in turn, positevly relates to the effectiveness of managing a strategic duality at the MNeS' organizational level: the counterweight logic (emphasizes an alternative strategic imperative); the hyprid engine logic (development of a balanced perspective: the creation of structures and systems that support equal focus at two points), and; the flywheel logic (creates enhanced ownership of the integrated view at lower levels within the organization, it supports the development of a shared point of view among the employee level) are the mechanisms for achieving contextual ambidexterity, in terms of shiftng employee's singular focus into a dual focus.

Organizational ambidexterity is positively related to MNEs' new product development and commercialization of Chinese MNEs; Also, CEO's preference of risks and opportunities in international market plays a significant moderating role on the relationship between ambidextrous capabilities and MNEs' product innovation performance Intellectual capital (human individual level, social - individual level, and organizational capital) of employees positevly relate to organizational ambidexterity which in turn positively affects company performance. Culture plays a contextual role (contextual variable), since the findings are mixed regarding the impact of the three types of capital resources on organizational ambidexterity across both countries 


\section{5}

Kao et al. 2016

Yan et al. 2016

Gebauer et al. 2017

Empirical

Quantitative Survey

Empirical Qualitative

Empirical Qualitative
Josserand et al. 2017 questionnaires from flight attendants

28 interviews, Archival data, $72 \quad \mathrm{CEO}$ speeches, office emails, research memos, 15 email surveys, internal circulations, virtual community

primary

semi-

structured

interviews)

and secondary

data from 20

international

organizations

33 semistructured interviews
Intrinsic motivation positively relates to ambidextrous behaviour among fron-line employees, which in turn enhances service perfomrance. Emotional

Individual Intelligence positively moderates the relationship between intrinsic motivation and individual (employee) ambidexterity, while a proactive personality and extrinsic reward negatively moderate it

Organizational learning at the team and individual level enabled technology-oriented

ambidexterity; organizational learning at the organizational and team level enabled the management-oriented

ambidexterity; organizational learning at the individual and interorganizational levels enabled market-oriented ambidexterity. All 3 types of ambidexterity form the organizational ambidexterity

Ambidexterity positively relates to business model innovations. In order for organizations to become ambidextrous, the following antecedents are identified: the need to assign job responsibilities on individual entrepreneurs themselves that balances their efforts for exploration and exploitation

The exploration and exploitation of external networks at the individual level provide the basis for exploration or exploitation activities at the business unit level. Individual network connections, that include both strong and weak ties, provide access to knowledge that is translated into possible opportunities for exploitation and exploration at the business unit levels. Also, 3 managerial conditions act as moderators on the relationship between employee social capital (network ties) and business unit ambidexterity: 1) managerial autonomy, 2) the development of a network culture that emphasizes on collaboration, information sharing and client centricity - stimulating the development of individual networks, and 3) developing organized network redundancies managers must encourage all employees to develop their own 
Vahlne \& Jonsson, Empirical $\begin{aligned} & \text { Qualitative } \\ & \text { Case Study }\end{aligned}$ 2017

Child et al 2017
82 interviews, documents, and observation studies

180 SMEs, indepth interviews

13 in-depth interviews and 7 thought experiments with Individual

Gabrielsson, Empirical 2017 client networks by using existing contacts or developing new ones which leads to the development of multiple contacts with external stakeholders on specific hierarchical levels and functions, a network of organized redundancies

The findings, among other, show that ambidexterity is positively related with the profitable globalization process of companies: contextual ambidexterity - each individual performs both exploratory and exploitative activities - operates as a success factor for the profitable globalization of companies at the eraly years of their development; structural ambidexterity - top management or dedicated units take action with the purpose to institutionalize ambidexterity takes place after the organizations are globalized and become large and complex. Time is a conditional factor on this relationship One of the business models for international markets prevail among SMEs is the ambidextrous explorer (ambidexterity). The likelihood of SMEs adopting one business model rather than another is to a high degree predictable with reference to a small set of factors: industry, level of home economy development, and decision-maker international experience. SMEs in which the key decision-makers have previous experience of international business (individual level of analysis) prior to joining or founding the firm are more likely to adopt the ambidextrous explorer business model

This study focuses in the context of in international new ventures operating in high-tech business-tobusiness markets. The ambidexterity of entrepreneurs allows them to simultaneously use the effectual process to explore and create a new market, and the causal process to exploit the existing market, which in turn, positively 


$\begin{array}{lllll} & & & 146 \quad \text { team } & \\ \text { Bresciani et } & \text { Empirical } & \begin{array}{l}\text { Quantitative } \\ \text { Survey }\end{array} & \begin{array}{l}\text { participants } \\ \text { from 43 Smart }\end{array} \text { Project } \\ \text { al. } 2017 & & \begin{array}{l}\text { City IoT } \\ \text { projects }\end{array} & \end{array}$

Snehvrat \& Dutta, 2018

\section{Empirical Qualitative}

38

\section{interviewees}

and 51 Team interviews in total relates to the development of entrepreneurial marketing (market creation, innovativeness, proactiveness, value co-creation, customer intensity, resource leveraging, risk management) by INVs. Uncertainty (internal uncertainty, market turbulence and technological uncertainty), is a conditional factor

MNEs operating through alliances in Smart Cities (context), need to develop knowledge management capabilities (knowledge creation and knowledge integration) combined with information and communication technologies capabilities (ICT internal use, ICT collaboration, ICT communication) if they want to obtain greater ambidexterity performance at the project portfolio level

Ambidexterity is achieved based on the following antecedents: same team focuses on both exploration and exploitation with the help of metaroutines (Ostensive - Voice of Customer, Partnership, Lean Processes and Structures, Commonality, esourcing - and performative aspects of metaroutine: creative recombination, leadership exclusive contracts, need to complement each other to be able to aid ambidexterity). Decisions are made across various levels; the role of top management is to have the ownership of the metaroutine and its governance; the roles of employees are clearly defined with coordinators focusing on inter group consistency; in terms of the skills of employees, there is a combination of coordinators and specialists. Team ambidexterity positevly relates to new product introduction 


\section{Figure 1: Search Strategy}

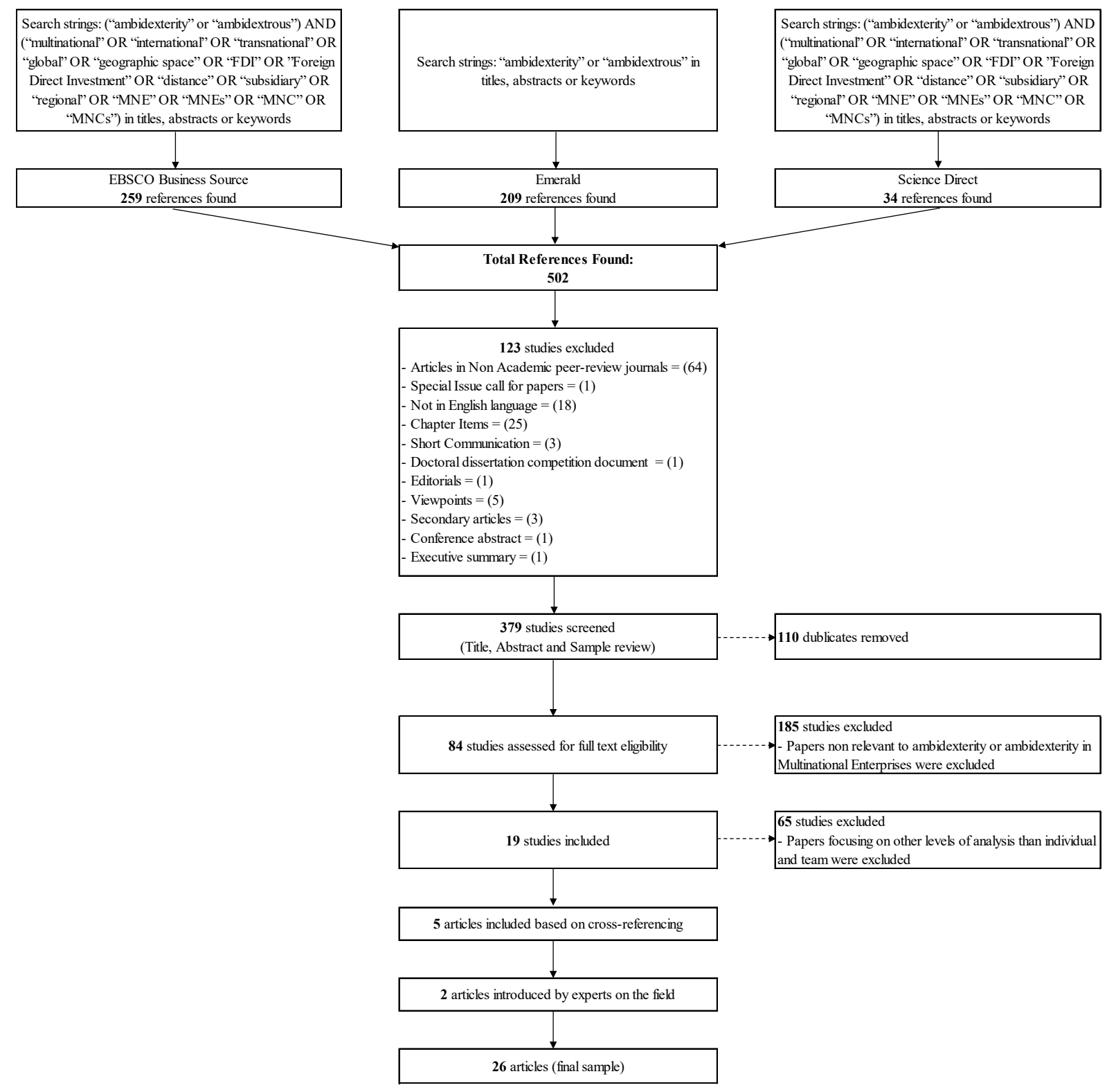


Figure 2: Field of journal that the included articles are published

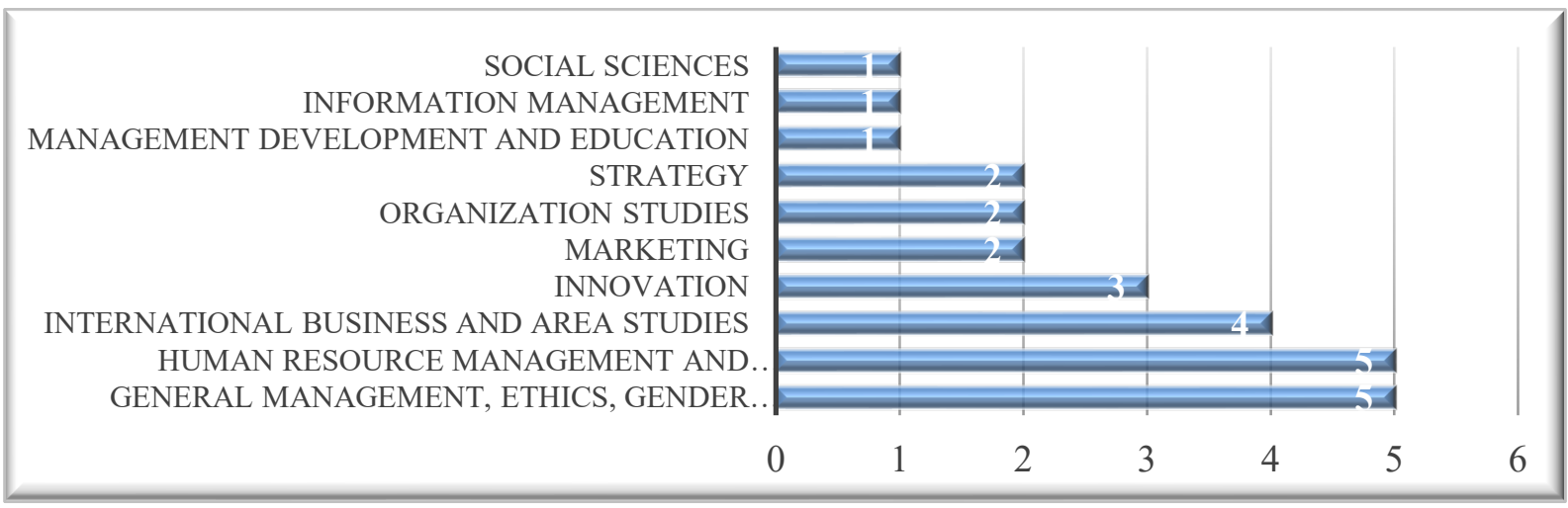

Figure 3: First author's Geographical Location

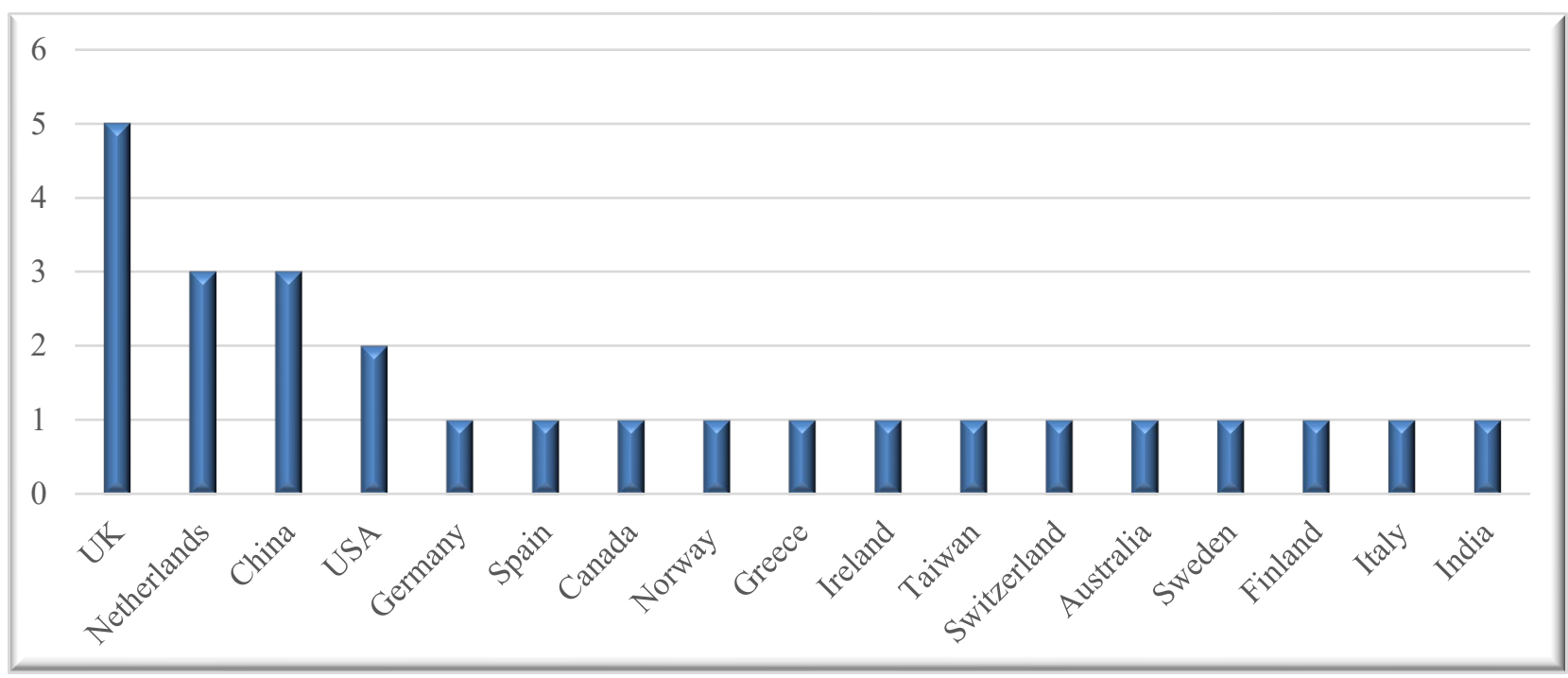


Figure 4: Relationship between type of methodology and year of publication
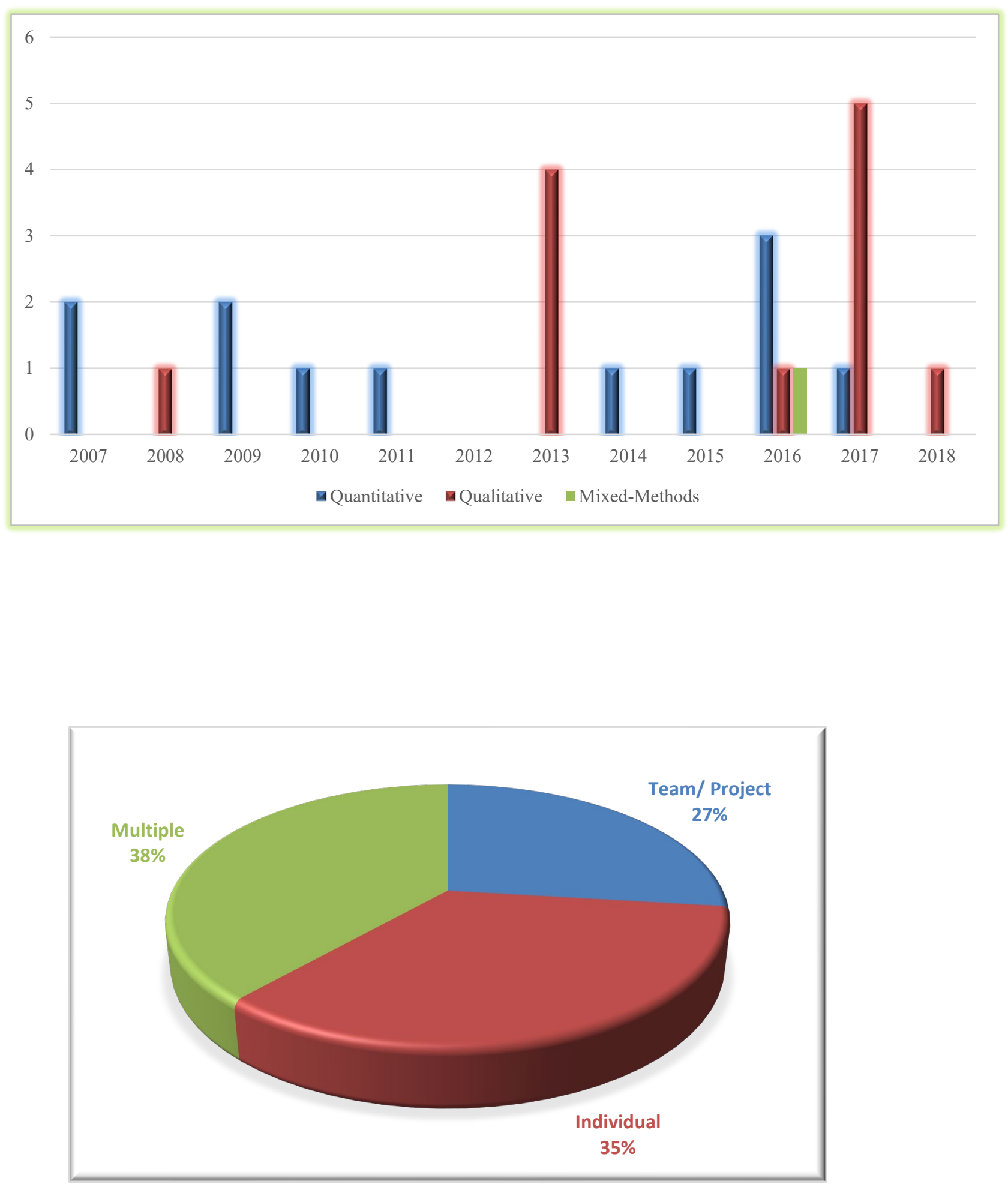
Figure 5: Organizing Framework

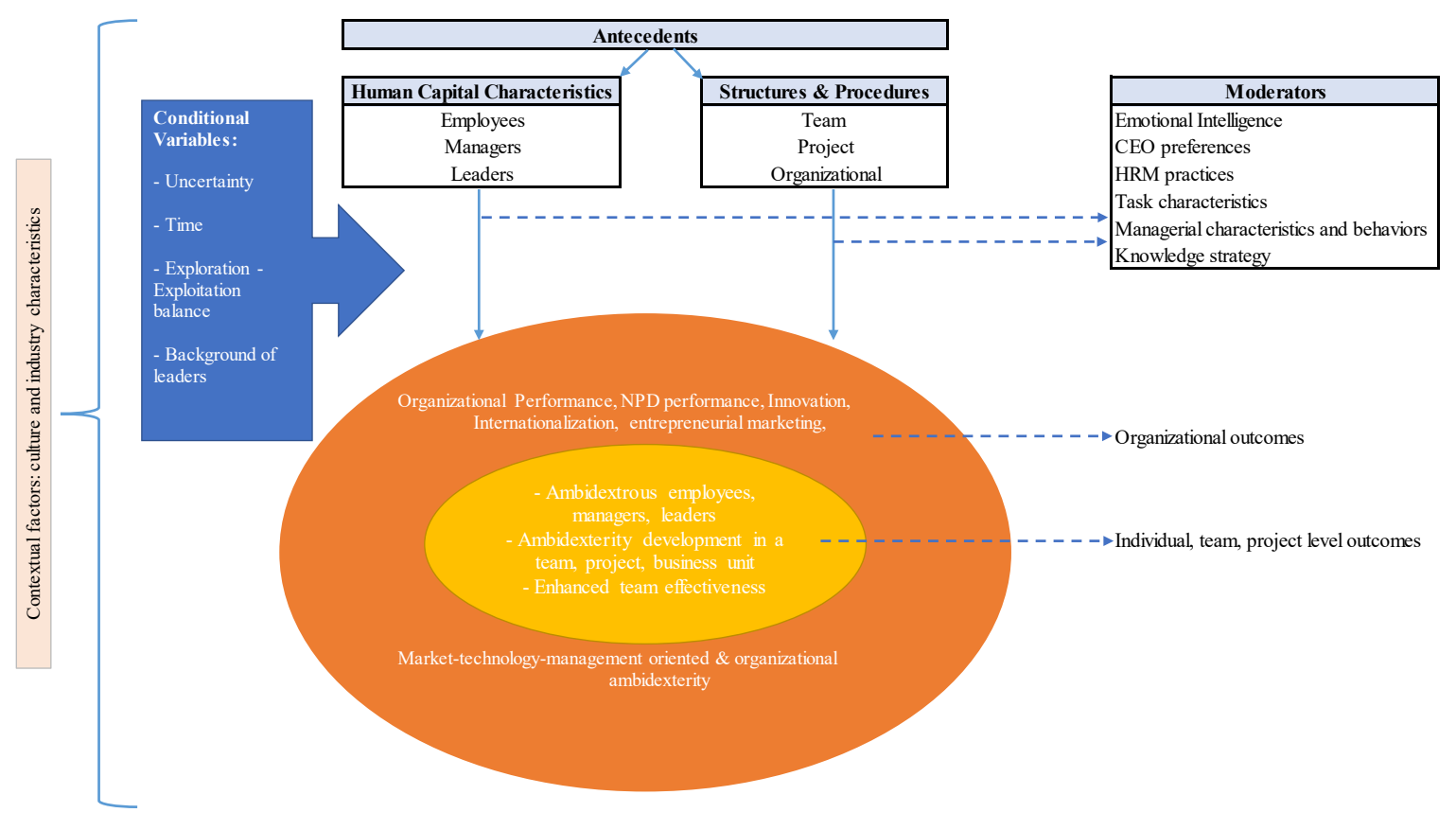


Figure 6: Conceptual Framework of micro-level ambidexterity and MNEs - Part 1

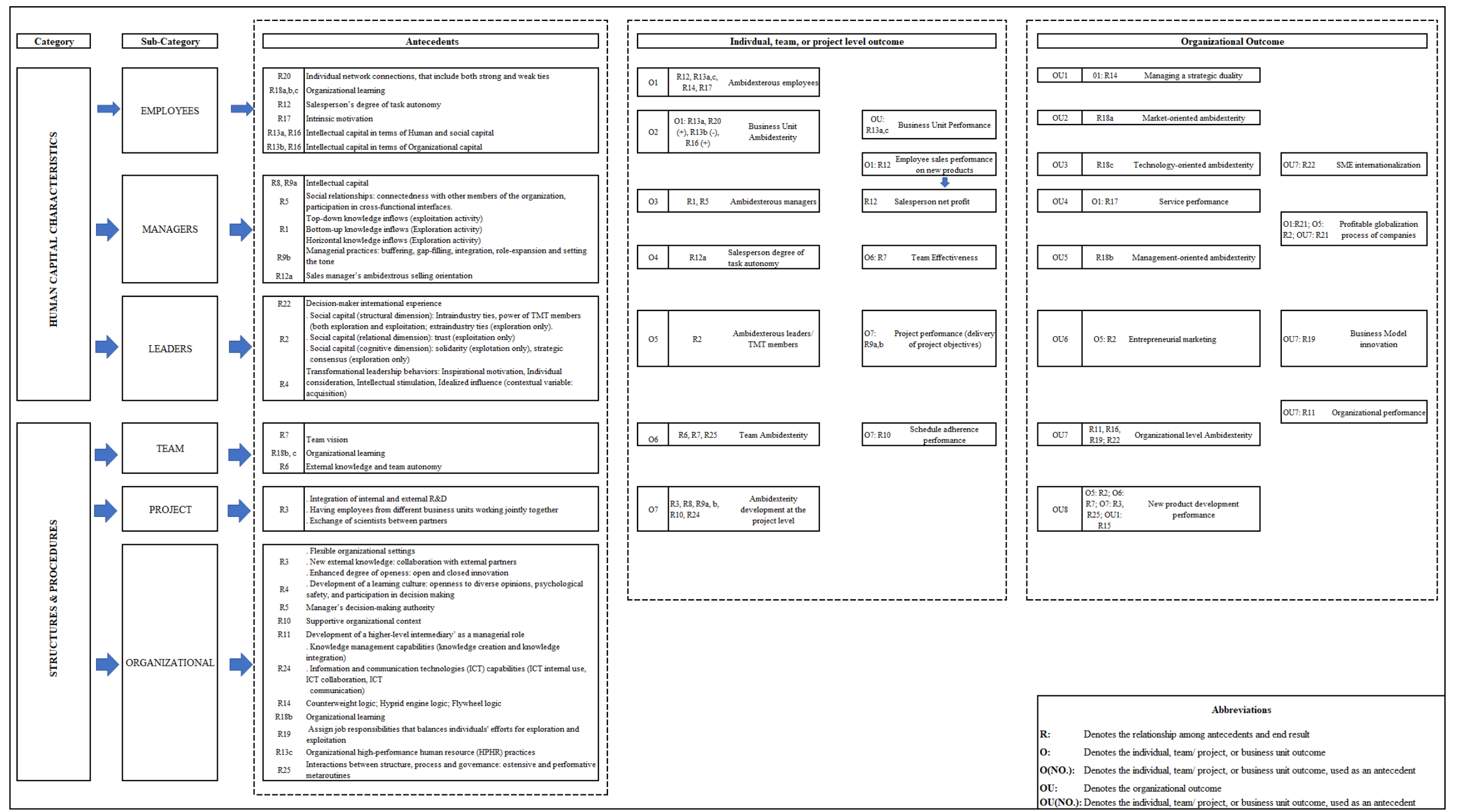


Figure 7: Conceptual Framework of micro-level ambidexterity and MNEs - Part 2

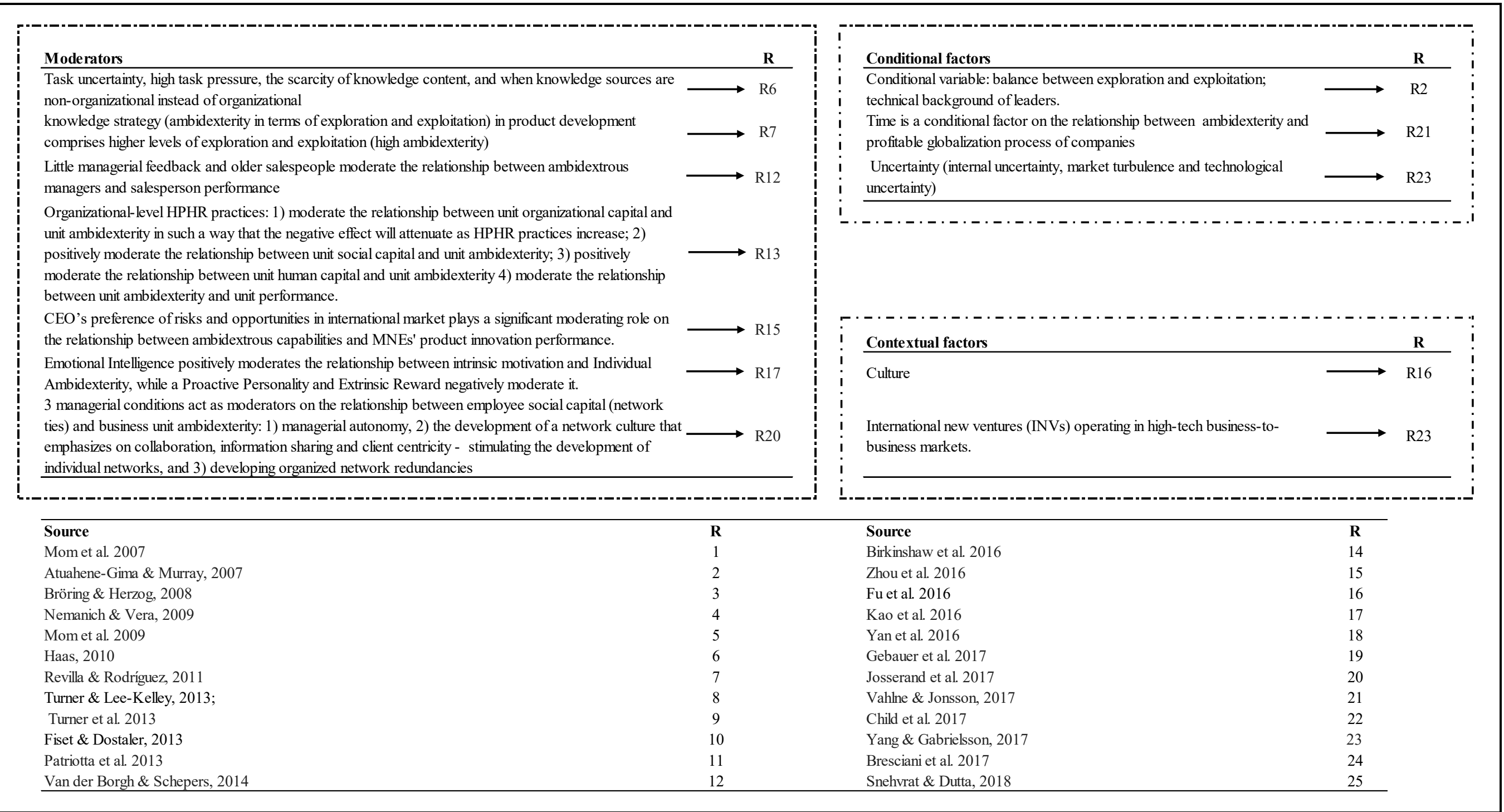

